\title{
Numerical and experimental investigation of the metering characteristic and pressure losses of the rotary tubular spool valve.
}

\author{
Ivan Okhotnikov ${ }^{\mathrm{a}, \mathrm{b}, *}$, Karem Abuowda ${ }^{\mathrm{a}}$, Siamak Noroozi ${ }^{\mathrm{a}}$, Philip Godfrey \\ ${ }^{a}$ Department of Design and Engineering, Faculty of Science and Technology, Bournemouth University, Poole House, Talbot Campus, Fern \\ Barrow, Poole, Dorset, BH12 5BB, United Kingdom \\ ${ }^{b}$ Hydreco Hydraulics Limited, 32 Factory Road, Poole, Dorset, BH16 5SL, United Kingdom
}

\begin{abstract}
This paper presents the results of numerical and experimental performance evaluation of the rotary tubular spool valve. The aim of this work is to develop further the novel design of the tubular spool valve by confirming experimentally the validity of the simulation model and its results, thereby proving the valve's potential to represent a feasible and more efficient alternative to conventionally used translation spool valves avoiding the use of two stage valve configurations. In this research the valve performance is assessed through numerical modelling and experimental studies of its metering characteristic and pressure losses. This paper demonstrates that the used valve model yields the results, which agree well with the conducted experimental study. Therefore, validation of the numerical model and the modelling results in the form of theoretical valve characteristics was accomplished. Firstly, the paper presents details of a numerical approach employed to evaluate valve performance and then analyzes the simulation results. Next, the valve performance is experimentally validated by testing a prototype valve on a hydraulic test rig capable of measuring the volume flow rate, pressure levels in up- and downstream lines of the valve across the entire spool angular stroke. Initially, average discrepancies between modelling and test results were $52.46 \%$ for the metering and $82.78 \%$ for the pressure loss characteristics. Correcting the model geometry aimed at eliminating differences between the valve model and the practically used prototype-test rig system enabled reduction of the error between experiment and modelling by $47.75 \%$ for the pressure loss function. This confirmed validity of the simulated characteristics of the valve. The benchmark comparison of pressure losses confirmed average $71.66 \%$ energy dissipation reduction compared to the industry-available analogue valve.
\end{abstract}

Keywords:

Computational fluid dynamics, experiment, validation, valve

\section{Introduction}

Fluid power offers a series of advantages unavailable to other drives, especially in applications requiring significant mechanical power output. Among the assets are high power density, reliability and a lower operating cost compared to competing technologies. Power hydraulics has a wide operating bandwidth. That enables fast starts, stops, and reversals. Working fluid in these systems performs power transmitting, lubricating and heat averting functions [1]. Moreover,

\footnotetext{
${ }^{*}$ Corresponding author

Email addresses: iokhotnikov@bournemouth.ac.uk (Ivan Okhotnikov), kabuowda@bournemouth.ac.uk (Karem Abuowda), snoroozi@bournemouth.ac.uk (Siamak Noroozi), pd.godfrey@ntlworld.com (Philip Godfrey)
}

1 due to the large bulk modulus of hydraulic mineral 2 oil, a fluid power drive is less sensitive to impact loads, provides natural damping and, thus, is more reliable than mechanical transmissions [2]. These factors have made hydraulics indispensable for high power applications and ensured its dominance among power drive technologies. 


\begin{tabular}{|c|c|}
\hline \multicolumn{2}{|l|}{ Nomenclature } \\
\hline \multicolumn{2}{|l|}{ Latin } \\
\hline$A$ & Area, $\mathrm{mm}^{2}$ \\
\hline$A_{v}$ & Van Driest coefficient \\
\hline$C_{d}$ & Discharge coefficient \\
\hline$C_{\varepsilon 1}, C_{\varepsilon 2}, C_{\mu}, C_{B}$ & Constants in the $k-\varepsilon$ model \\
\hline$d, D$ & Diameter, mm \\
\hline$D_{h}$ & Hydraulic diameter, $\mathrm{mm}^{2}$ \\
\hline$f_{1}, f_{2}, f_{\mu}$ & $\begin{array}{l}\text { Lam and Bremhost's damping } \\
\text { functions in } k \text { - } \varepsilon \text { turbulence model }\end{array}$ \\
\hline$F$ & Force, $\mathrm{N}$ \\
\hline$k$ & Turbulent kinetic energy, $\mathrm{m}^{2} \mathrm{~s}^{-2}$ \\
\hline$K$ & Karman constant \\
\hline$l, L$ & Length, characteristic length, $\mathrm{mm}$ \\
\hline$p$ & Pressure, $\mathrm{MPa}$ \\
\hline$P$ & Power, W \\
\hline$Q$ & Volume flow rate, $\mathrm{L} \mathrm{min}^{-1}$ \\
\hline$R_{T}, R_{y}$ & Turbulence and velocity-average \\
\hline & Reynolds number \\
\hline $\operatorname{Re}$ & Reynolds number \\
\hline$S$ & Perimeter, mm \\
\hline$t$ & Time, s \\
\hline$u_{i}$ & $\begin{array}{l}\text { The } i \text {-th component of the fluid } \\
\text { velocity vector, } \mathrm{m} \mathrm{s}^{-1}\end{array}$ \\
\hline$u^{+}$ & $\begin{array}{l}\text { Dimensionless longitudinal } \\
\text { velocity }\end{array}$ \\
\hline$v, V$ & $\begin{array}{l}\text { Average, characteristic velocity, } \\
\mathrm{m} \mathrm{s}^{-1}\end{array}$ \\
\hline$y$ & Distance from the wall surface, $\mathrm{m}$ \\
\hline$y^{+}$ & Dimensionless wall distance \\
\hline$x_{i}$ & $\begin{array}{l}\text { The } i \text {-th component of the } \\
\text { coordinate vector, } \mathrm{m}\end{array}$ \\
\hline Greek & \\
\hline$\delta_{i j}$ & Kronecker function \\
\hline$\varepsilon$ & $\begin{array}{l}\text { Turbulent dissipation rate, } \\
\mathrm{m}^{2} \mathrm{~s}^{-2} \text {, strain }\end{array}$ \\
\hline$\mu$ & Dynamics viscosity, Pa s \\
\hline$\mu_{t}$ & $\begin{array}{l}\text { Turbulent eddy viscosity } \\
\text { coefficient }\end{array}$ \\
\hline$v$ & Kinematic viscosity, $\mathrm{m}^{2} \mathrm{~s}^{-1}$ \\
\hline$\rho$ & Density, $\mathrm{kg} \mathrm{m}^{-3}$ \\
\hline$\sigma_{k}, \sigma_{\varepsilon}, \sigma_{B}$ & Constants in the $k-\varepsilon$ model \\
\hline$\tau_{i j}$ & Reynolds stress tensor, MPa \\
\hline$\tau_{w}$ & Wall shear stress, MPa \\
\hline$\phi$ & Spool angular position, ${ }^{\circ}$ \\
\hline
\end{tabular}

\section{$\bar{x}$}

Acronyms

AEM

CAD

CFD

DAS

FM

PRV

PT

RTSV

SM

TT

VAC

VDC

VFD
Mean value of $x$

Asynchronous Electric Motor

Computer Aided Design

Computational Fluid Dynamics

Data Acquisition System

Flow Meter

Pressure Relief valve

Pressure Transducer

Rotary Tubular Spool Valve

Stepper Motor

Torque Transducer

Volts of Alternating Current

Volts of Direct Current

Variable-Frequency Drive

However, fluid power possesses several drawbacks. Tight clearances between mechanical parts require extremely clean working fluid free from solid particles, dissolved gasses and air. It necessitates regular and strict supervision of the oil's contamination level during an exploitation period. Other shortcomings are low flexibility and high non-linearity of hydraulic control relative to electromagnetic counterparts [1]. Hydraulics is also prone to oil leakage through seals, mechanical contacts and connections [3], which can cause spillages and environmental pollution.

The presence of valves modulating the output velocity of the hydraulic actuator remains the main design feature of the state of the art power hydraulic systems due to robustness and a relatively low cost of this solution [4]. Flow- and pressure-regulating valves enable a link between the source of hydraulic power and its consumers, implement complex logic of actuators operation in a working cycle. The actuator's speed regulation is fulfilled through throttling adjustment, which realized by changing the valve's spool position. The spool position determines an orifice area, which in turn defines valve's hydraulic resistance. The flow rate to the actuator as well as its output velocity changes according to this area.

The common trait of valve-controlled systems is prevalence of throttling losses due to a resistive nature of flow regulation. Since the flow regulation is being fulfilled by restraining the flow inside the valve, excessive fluid power is dissipated in a form of vortices with substantial viscous friction losses and heat generation in them. These result in poor energy efficiency of the valve as well as the entire hydraulic system it is installed in. The review of the industrial state-of-the-art and research advancements in 
development of direct drive proportional spool valves ${ }_{106}$ [5] confirms optimization of the flow paths through the ${ }_{107}$ valve to lessen flow disturbances is viable, well known ${ }_{108}$ and tested technique to solve efficiency issues in valves 109 and reduce pressure losses.

Judging by flow streamlines in the conventionally used spool and seat valves obtained through visualization of flow paths with CFD [6], [7], it has been concluded that, firstly, exact geometry of the valve is a sole factor defining flow trajectories, pressure losses and hence efficiency of the valve; secondly, streamlining flow paths is a way to improve valve efficiency and to reduce flow forces on a spool [8]; and finally, the easiest way to implement streamlining is to remove unnecessary turns and sudden cross-sectional changes of flow paths, which are in abundance in linear spool valves. The most obvious way to keep the flow route smooth is to rid of sudden U-turns. These considerations let to infer that rotary valves could provide more streamlined flow trajectories and ease of valve operation. Unlike conventional linear spool configurations, a rotating spool design especially with a hollow spool would create a much smaller net area of surfaces subjected to the flow forces, hence decreasing power consumption of a valve driving mechanism.

So far, the employment of rotary spools industrially is limited to manually driven on-off ball valves, flow dividers, plug and steering valves, which are used in the steering systems of wheeled vehicles [9]. In the rotary ball valves, usually a rotary spool is spherical in a cross section with drilled through-holes serving as flow paths. In valves with cylindrical spools, flow paths are milled on the external cylinder of the spool, imposing sudden changes in direction and a cross sections of flow paths. Although these valve structures still include undesirable U-turns in flow trajectories [10], the required effort to operate them is comparable with currently used linear sliding spools [11], their dynamic performance is also similar to conventional linear spools [12], [13].

Among multitude patents dedicated to the rotary valve structures, there are design solutions suggesting a tubular spool as the main throttling part. Embodying the approach of mobile surfaces minimization and using rotary control motion, these concepts represent a promising and under-studied class of control valve designs suitable for high-power hydraulics applications. The first found patents proposing such structures were filed in the middle of the last century by Husley and Erwin as rotary sleeve valves [14] and [15].

The present research aims at validating the used methodology to obtain CFD simulated performance characteristics of the previously suggested design of the rotary tubular valve, thereby, confirming its flow controlling capabilities and potential to improve controllability and energy efficiency of spool valves. Experimental validation was employed to investigate flow forces and pressure drop in conventional directional control valves [16], to explore performance of innovative designs of linear spools [17] as well as rotary valves [18]. Overall, these would allow to develop further this promising design and to prove that the rotary spool valve is a viable competitor to conventional linear spool valves in terms of metering capabilities and energy efficiency.

\section{Rotary tubular spool valve}

\subsection{Design}

The design of the rotary tubular spool valve (RTSV) and theoretical analysis of flow physics within it have been reported in details in the authors' previous work [19]. The current research investigates the same valve structure, although the down scaled version, which had enabled experiments on a test rig described in the following sections.

The cut section in fig. 1 illustrates the RTSV design and operation. The oil enters the RTSV through the circular inlet area $A_{i n}$. Then, it flows into the central chamber of the spool 1 . The chamber is formed by spool's internal cylindrical and conical surfaces and the circular area $A_{1}$. From the central chamber the oil passes through two throttling orifices, which are created by overlapping openings on the spool 1 and the sleeve 2, see fig. 1. Next, the oil finds its way from the orifices to the annular oil collecting channel, or chamber, with the cross-sectional area of $A_{a n}$, which encircles the sleeve. The collecting chamber is connected to the outlet hydraulic port with the circular area $A_{\text {out }}$, which is designed to be equal to $A_{\text {in }}$.

To keep hydraulic disturbances to the flow as small as possible, the cross-sectional area of the entering flow $A_{\text {in }}$ should be maintained throughout valve's internal passages up to the exit port with the area $A_{\text {out }}$. This approach results in the design criterion for selecting cross-sectional areas of the valve's channels.

Since there are two throttling orifices on the spool and the total flow is split in two jets, the annular area of the flow in the collecting chamber $A_{a n}$ needs to be equal to a half of the inlet flow's cross-sectional area $A_{i n}$, i.e. 


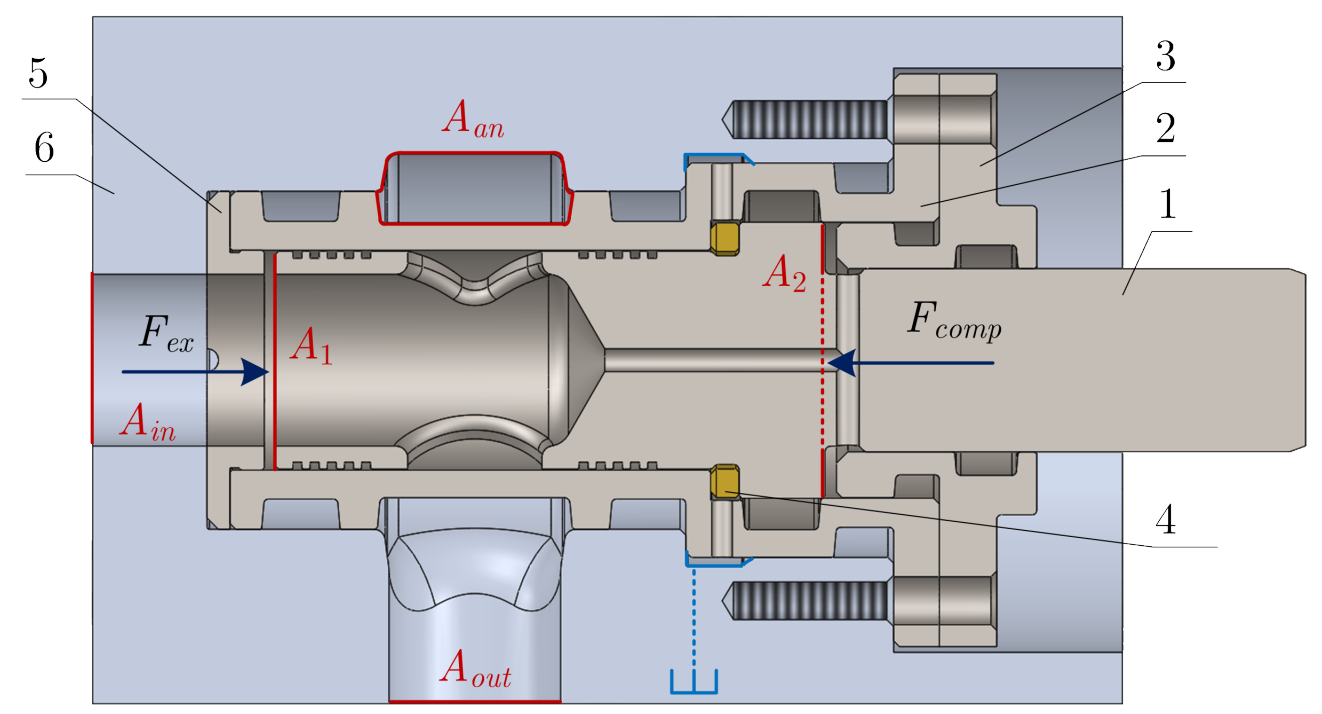

Figure 1: The cutaway section of the RTSV. Original parts: 1 - spool, 2 - sleeve, 3 - lid, 4 - thrust bearing, 5 - guiding sleeve, 6 - valve body. The region inside the spool to the right of the area $A_{1}$ - the spool central chamber or cavity. The annular region with the cross section of $A_{a n}-$ the cross-section of the single branch of the collecting channel or chamber. $A_{\text {in }}$ and $A_{\text {out }}$ - inlet, supply and outlet, service ports respectively. $A_{2}-$ the annular area of the spool back, or compensating chamber.

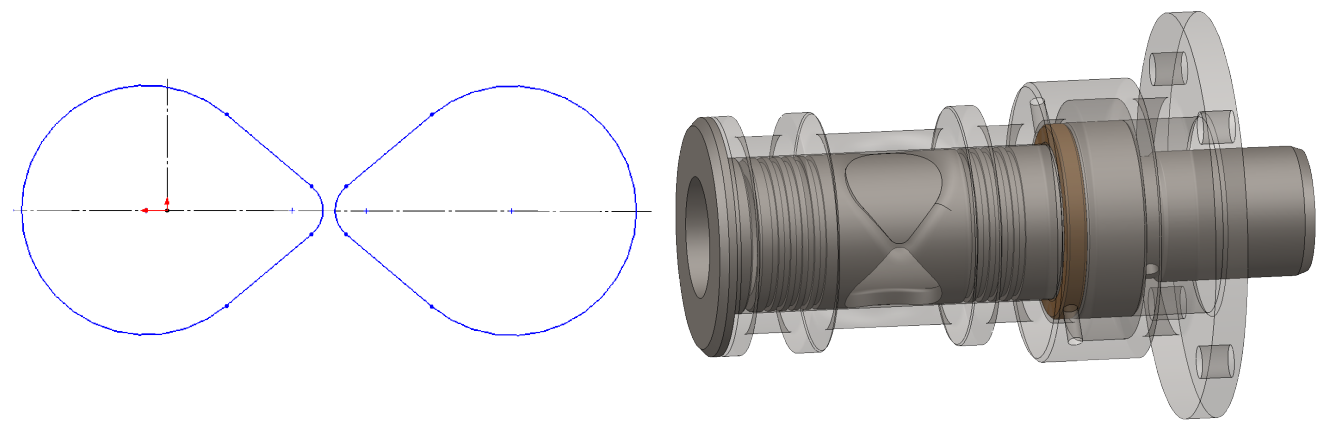

(a) $\phi=0^{\circ}$, fully closed.
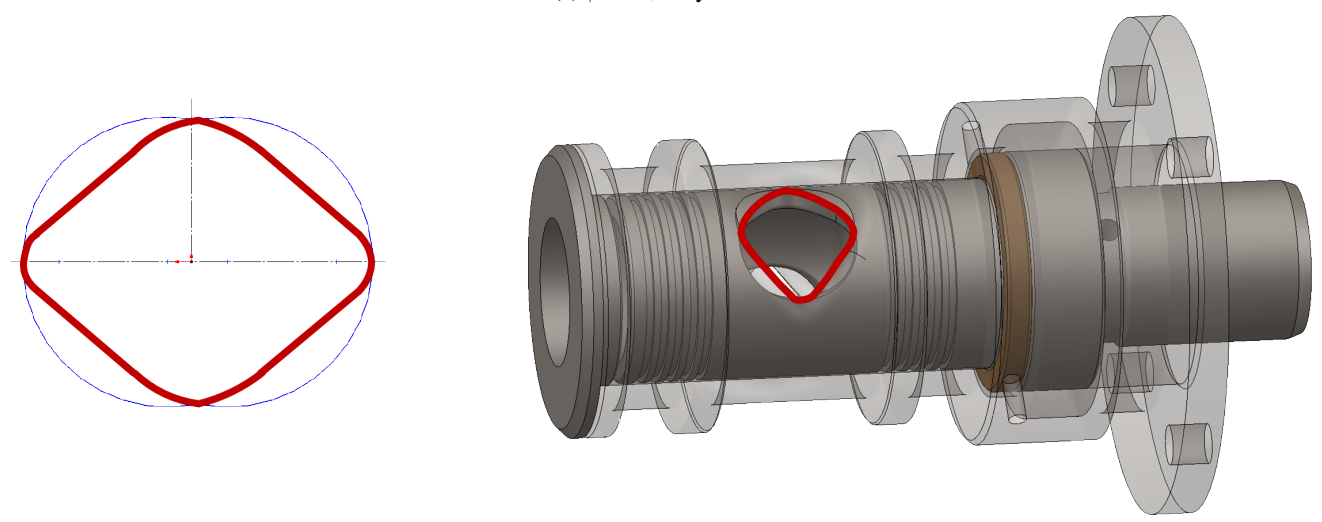

(b) $\phi=90^{\circ}$, fully open

Figure 2: The single throttling orifice at the extreme states. Left - overlap of the unfolded throttling profiles of the spool and sleeve openings. Right - location of the single throttling orifice on the spool-sleeve assembly. 


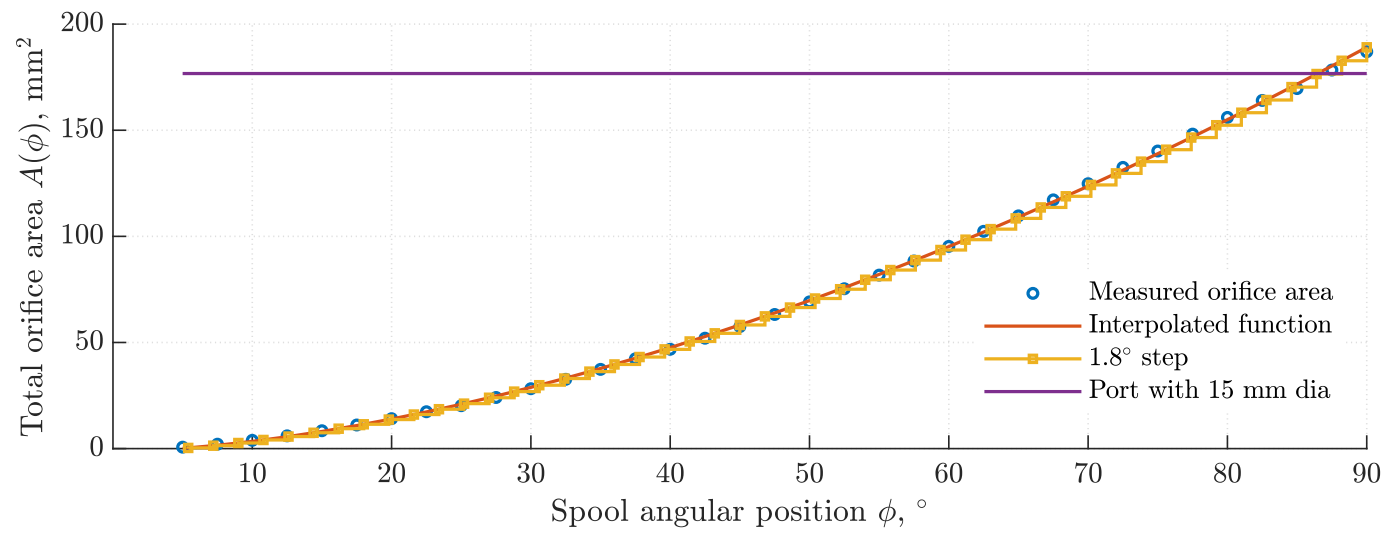

Figure 3: The total orifice area function, $A(\phi)$.

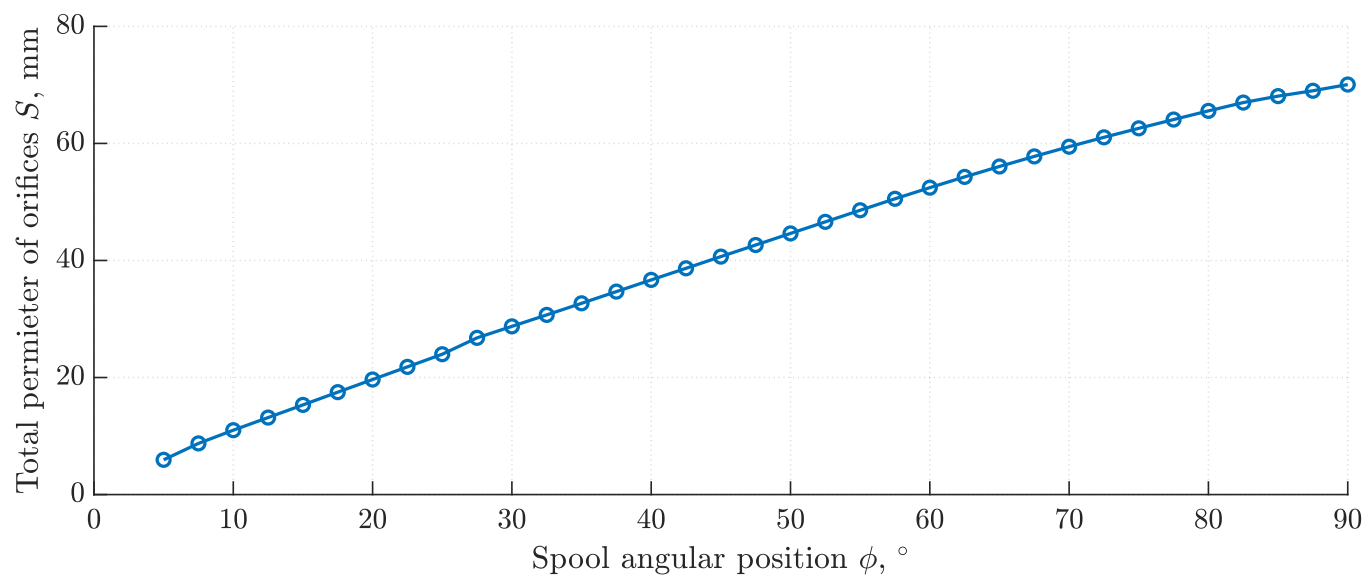

Figure 4: Total perimeter of the throttling orifices, $S(\phi)$.

163

$$
A_{\text {in }}=A_{\text {out }}=2 A_{\text {an }} .
$$

At any moment the tubular spool is exposed to the pump pressure $p_{p}$ acting on the spool's circular surface $A_{1}$. This creates the extruding force $F_{e x}$ that pushes the spool out from the valve body.

$$
F_{e x}=p_{p} A_{1}
$$

To compensate this force and to locate the spool in a ${ }_{168}$ certain axial position, the oil is directed through the 169 axial channel inside the the spool to its back chamber. 170 There, the oil acts on the annular area $A_{2}$ with the ${ }_{171}$ pump pressure $p_{p}$, which creates the compensating 172 force $F_{\text {comp }}$.

$$
F_{\text {comp }}=p_{p} A_{2}
$$

Therefore, assuming pressure levels are equal in the spool central and the back chambers, the design criterion for selecting areas $A_{1}$ and $A_{2}$ as well as ensuring spool axial stabilization is

$$
\begin{gathered}
F_{\text {comp }} \geq F_{e x} \\
A_{2} \geq A_{1}
\end{gathered}
$$

If the annular area $A_{2}$ exceeds the circular area $A_{1}$, the compensating force surpasses the ejecting force, i.e. $F_{\text {comp }}>F_{e x}$. In this case, the spool is pushed against the brass thrust bearing 4 in fig. 11. The bearing's material needs to ensure a low friction pair between the steel or aluminum spool and the bearing.

17 The thrust bearing features radial grooves to allow the oil leakage from the spool-sleeve clearance to drain to the tank. In fig. 1 1 the groove, which is cut in the body 6 
and is outlined in blue, collects this leakage and drains 225 it to the tank. The drainage channel also collects the oil flowing from the spool back chamber through the 226 sleeve's groove of the sealing rings. Combined internal leakage from these two paths enables hydrodynamic bearing on spool and thrust bearing mating surfaces.

The guiding sleeve 5 serves to facilitate dismantling of 230 the valve in case replacement of any internal parts is 231 needed. Semi-circular cuts on the sleeve bottom plane ${ }_{232}$ can be used to pull all valve inner parts from the body 6.233 The lid 3 ensures all immovable parts are securely fixed 234 by tightening screw fasteners to designated threaded 235 blind holes on the housing 6 .

\subsection{Operation}

The throttling pair in fig. 2 performs regulation of the flow area and, hence, the flow rate passing through the RTSV. The flow rate is directly proportional to the overlap area between the slots of the rotary actuated spool and the static sleeve. The total area of the ${ }_{243}$ throttling orifices varies in a range between the fully 244 closed and full open states shown in figs. $2 \mathrm{a}$ and $2 \mathrm{~b} 245$ respectively. Therefore, the angular position of the 246 spool $\phi$ in the sleeve defines the openings' overlap, the ${ }_{247}$ total orifice area $A$ and the resultant oil's flow rate $Q . \quad 248$

The total orifice area is also a function of each window ${ }^{249}$ profile. In the current research, the shape of openings ${ }^{250}$ was chosen to be the same for the spool and the sleeve, with areas chosen according to above mentioned design criteria, i.e. the maximum total orifices area at the fully open state is designed to be as close as possible to the inlet flow cross section ensuring the least resistance to the flow.

The openings on the sleeve and the spool form the orifice with the total opening area function $A(\phi)$ shown in fig. 3 The increase of the area is nonlinear with a more gradual increment at lower angles of opening. The slow non-linear change in the area at the start of actuation is a special design feature of the RTSV. The dependency at $\phi>50^{\circ}$ of the spool angular position is steeper, reaching the total orifice opening of $186.99 \mathrm{~mm}^{2}$. The graph also includes the area of the ${ }^{251}$ hydraulic inlet port with the diameter of $15 \mathrm{~mm}$, which 252 results in the inlet flow cross section of $176.71 \mathrm{~mm}^{2}$. The step-wise line in fig. 3 illustrates the area increase in the case the spool position is defined with a conventional stepper motor with $1.8^{\circ}$ step. Additionally, the orifices's perimeter was measured, see fig. 4, to 253 enable Reynolds number estimation in the following 254 section.

\section{CFD modelling}

\subsection{Turbulence model}

In the intended application of the RTSV, which is high pressures and high flow rates, the fluid flow inside the valve tends to be turbulent. In the used CAD-embedded CFD software, FloEFD suit, the Favre-averaged Navier-Stokes equations are used, where the effects of the flow turbulence on the mass-averaged flow parameters are considered. The applied Favre averaging method also accounts for fluctuations of fluid density and temperature [20].

To close the system of Navier-Stokes equations, transport equations for the turbulent kinetic energy and its dissipation rate are employed, the so-called $k-\varepsilon$ model [21]. The adopted model meets accuracy and reliability requirements in the considered valve study and performs satisfactorily in solving fluid power problems [22].

In FloEFD the classical two-equations $k-\varepsilon$ empirical model for simulating turbulence in fluid flow is used as it requires the minimum amount of additional information to define the flow [23]. The modified $k$ - $\varepsilon$ turbulence model with damping functions [24] describes laminar, turbulent, and transitional flows of homogeneous fluids consisting of the following turbulence conservation laws [20], [25]:

$$
\begin{aligned}
& \frac{\partial \rho k}{\partial t}+\frac{\partial \rho k u_{i}}{\partial x_{i}}=\frac{\partial}{\partial x_{i}}\left(\left(\mu+\frac{\mu_{t}}{\sigma_{k}}\right) \frac{\partial k}{\partial x_{i}}\right)+ \\
& \tau_{i j}^{R}-\rho \varepsilon+\mu_{t} P_{B}
\end{aligned}
$$

$$
\begin{aligned}
\frac{\partial \rho \varepsilon}{\partial t}+\frac{\partial \rho \varepsilon u_{i}}{\partial x_{i}} & =\frac{\partial}{\partial x_{i}}\left(\left(\mu+\frac{\mu_{t}}{\sigma_{\varepsilon}}\right) \frac{\partial \varepsilon}{\partial x_{i}}\right)+ \\
C_{\varepsilon 1} \frac{\varepsilon}{k} & \left(f_{1} \tau_{i j}^{R} \frac{\partial u_{i}}{\partial x_{j}}+C_{B} \mu_{t} P_{B}\right)-f_{2} C_{\varepsilon 2} \frac{\rho \varepsilon^{2}}{k}
\end{aligned}
$$

Here $P_{B}$ represents turbulence generation due to buoyancy and can be written as

$$
P_{B}=-\frac{g_{i}}{\rho \sigma_{B}} \frac{\partial \rho}{\partial x_{i}},
$$

where $g_{i}$ is the component of gravitational acceleration in direction of $x_{i}$. The empirical $k-\varepsilon$ constants have the following typical values [21]: $\sigma_{k}=1, \sigma_{B}=0.9, \sigma_{\varepsilon}=$ 
1.3, $C_{\mu}=0.09, C_{\varepsilon 1}=1.44, C_{\varepsilon 2}=1.92$ and constant $C_{B}=1$ if $P_{B}>0$, and 0 otherwise.

Following Boussinesq assumption, the Reynolds-stress tensor for Newtonian fluids has the following form:

$$
\tau_{i j}^{R}=\mu\left(\frac{\partial u_{i}}{\partial x_{j}}+\frac{\partial u_{j}}{\partial x_{i}}-\frac{2}{3} \delta_{i j} \frac{\partial u_{k}}{\partial x_{k}}\right)-\frac{2}{3} \delta_{i j} \rho k .
$$

Here $\delta_{i j}$ is the Kronecker delta function (it is equal to unity when $i=j$, and zero otherwise), $\mu$ is the dynamic viscosity coefficient, $k$ is the turbulent kinetic energy and $\mu_{t}$ is the turbulent eddy viscosity coefficient, which is determined from

$$
\mu_{t}=\frac{f_{\mu} C_{\mu} \rho k^{2}}{\varepsilon} .
$$

Here $f_{\mu}$ is the turbulent viscosity factor. It is determined by the expression

$$
\begin{gathered}
f_{\mu}=\left(1-e^{-0.0165 R_{y}}\right)^{2}\left(1+\frac{20.5}{R_{T}}\right), \\
R_{y}=\frac{\rho \sqrt{k} y}{\mu}, \\
R_{T}=\frac{\rho k^{2}}{\mu \varepsilon}
\end{gathered}
$$

Lam and Bremhorst's damping functions $f_{\mu}, f_{1}, f_{2}{ }_{293}$ decrease turbulent viscosity and turbulence energy 294 and increase the turbulence dissipation rate when the ${ }_{295}$ Reynolds number $R_{y}$ based on the average velocity of ${ }_{296}^{295}$ fluctuations and distance from the wall becomes too ${ }_{297}$ small. When $f_{\mu}=1, f_{1}=1, f_{2}=1$ the approach ${ }_{298}$ obtains the original $k-\varepsilon$ model.

\subsection{Wall function}

To simulate fluid boundary layer effects near solids 302 within the $k-\varepsilon$ model a "two-scale wall function" 303 approach [26] is utilized. The FloEFD employs Van ${ }_{304}$ Driest's profiles [27].

When the number of fluid cells across the boundary ${ }^{300}$ layer more than 10, modelling of a laminar boundary ${ }^{30}$ layer is done via Navier-Stokes equations as part of 308 the core flow calculation. For turbulent boundary 309 layers proceeding from the Van Driest mixing length 310 [27], the FloEFD uses following dependency of 311 the dimensionless longitudinal velocity $u^{+}$on the ${ }_{312}$ dimensionless wall distance $y^{+}[23]$

$$
u^{+}=\frac{u}{\sqrt{\frac{\tau_{w}}{\rho}}}=\int_{0}^{y^{+}} \frac{2 d \eta}{1+\sqrt{1+4 K^{2} \eta^{2}\left(1-e^{-\frac{\eta}{A_{v}}}\right)^{2}}}
$$

Here $K=0.4504$ is the Karman constant and the Van Driest coefficient is $A_{v}=26$.

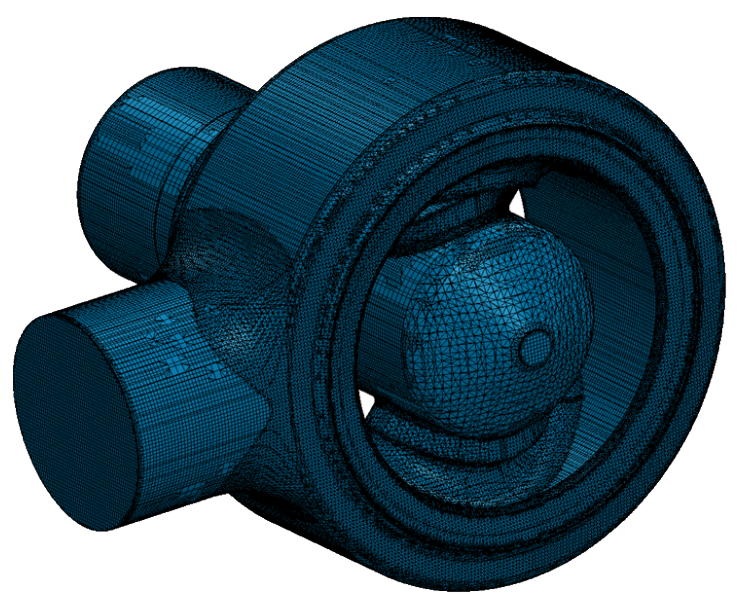

Figure 5: The mesh of the fluid subdomain with $\approx 1$ million fluid cells.

\subsection{Mesh}

The fluid subdomain was extracted from the three dimensional geometric model of the RTSV. Then, the fluid domain was split into cells with adjustable resolution. The governing partial differential Navier-Stokes and transport equations were solved in nodes, in centres of the mesh cells. The FloEFD solves the governing equations with a discrete numerical technique based on the finite volume discretization method.

Meshing in the FloEFD results in rectangular parallelepiped cells with orthogonal faces, see fig. 5 . The near-boundary cells are fractions of the original cells that are cut by the solid matter geometry boundary. Thus, the resulting near-boundary cells are polyhedrons with both axis-oriented and arbitrary oriented plane faces, partial cells. All physical and inertial parameters are referred to the mass centres of the cells within the control volume [21].

The module uses the immersed body meshing approach, which provides the structured Cartesian mesh with an irregular distribution of the mesh cells, which speeds up the search for data associated with neighbour cells and has been shown to deliver the lowest local truncation error. The approach also simplifies navigation on 


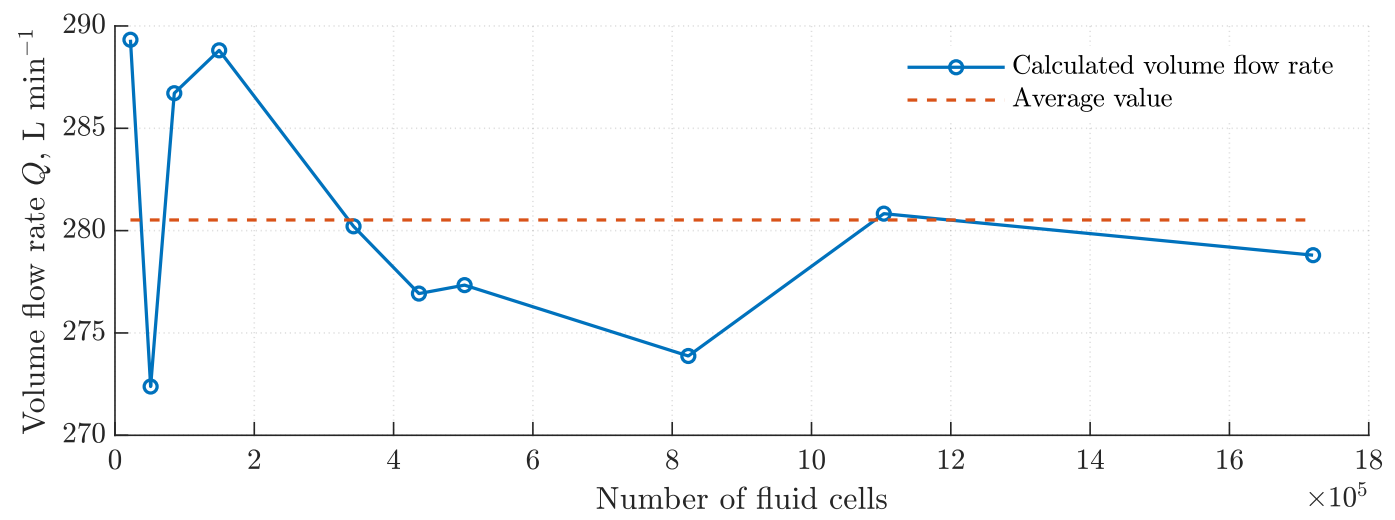

Figure 6: Grid independence study results. The mean value $\bar{Q}=280.46 \mathrm{~L} \mathrm{~min}^{-1}$, the standard deviation $\sigma=5.97 \mathrm{~L} \mathrm{~min}^{-1}$, which is $2.13 \%$ deviation from the mean value.

the mesh and to ensure robustness of the differencing 346 scheme by the absence of secondary skewed faces [28]. 347

Applied solution-adaptive refinement process allows ${ }^{348}$ further splitting the mesh cells the high-gradient flow regions, which cannot be resolved prior to 349 the calculation and merging the mesh cells in the low-gradient regions. It serves to minimize the spatial error arising from the discretization of the governing differential equations [28].

\subsubsection{Grid independence}

A grid independence analysis has been performed for ${ }^{356}$ the case of $\Delta p=1 \mathrm{MPa}$ pressure drop between 357 up- and downstream openings of the valve and the 358 spool angular position $\phi=90^{\circ}$ corresponding to the 359 full open state. For these conditions, several meshes 360 were created differing in a number of fluid cells from 361 22000 to 1700000 . The mean value of the computed ${ }_{362}$ flow rate between different meshes is equal to $\bar{Q}={ }_{363}$ $280.46 \mathrm{~L} \mathrm{~min}^{-1}$ with $2.13 \%$ fluctuations of the extreme 364 values around the average one.

The standard deviation is $5.97 \mathrm{~L} \mathrm{~min}^{-1}$, which is ${ }^{366}$ considered as an acceptable value to conclude that ${ }^{367}$ the obtained values ensure the convergence of the 368 solution regardless of the mesh resolution. The applied 369 mesh resolutions provide acceptable accuracy of the 370 computed results. The result of the mesh independence ${ }_{371}$ study is shown in fig. 6 .

The meshing for further parametric studies was selected ${ }^{373}$ such that it provides on average 1.1 million fluid cells 374 and 3 million partial cells on the surfaces bordering with 375 solid matter. The maximum cell size of the basic mesh 376 before the refinement process commences is $0.8 \mathrm{~mm}$. ${ }_{377}$
The chosen meshing setting guarantees a reasonable trade-off between computational time and accuracy for the simulations described further.

\subsection{Boundary conditions}

The specification of the boundary conditions consists of assigning the desired magnitude of the flow parameters to the fluid subdomain's openings and establishes the hydraulic problem to be solved by the FloEFD. In this study, a wall roughness and slip conditions were not imposed, there were no leakages through external sealing lids of the valve's fluid domain.

The first objective is to model metering performance of the valve by quantifying the valve's discharge coefficient $C_{d}(\phi)$ and the metering function $Q(\phi)$. In these parametric simulations, Dirichlet boundary conditions for the stationary turbulent fluid flow were used. Namely, boundary conditions for the valve inlet were selected as the static pressure of $p_{\text {in }}=$ $0.35 \mathrm{MPa}, 0.6 \mathrm{MPa}$ and $1.1 \mathrm{MPa}$. The valve outlet opening was subjected to the invariant static pressure of $p_{\text {out }}=0.1 \mathrm{MPa}$ corresponding to a pressure level of the "breathing" oil tank.

Thus, the boundary condition of the adopted pressure drop makes up a set of $\Delta p=0.25 \mathrm{MPa}, 0.5 \mathrm{MPa}$ and $1 \mathrm{MPa}$ pressure differentials. The magnitudes of the pressure differential were selected according to an usual margin of pressure levels in load sensing systems, which is in a range 10 bar to 20 bar [29], [30].

This set of hydraulic boundary conditions provided varying values of the pressure difference $\Delta p$, dictating the volume flow rate $Q$ passing through the orifice. For each variation of the specified input, the angular 


\begin{tabular}{|c|c|}
\hline Simulation type & Internal stationary turbulent flow simulation \\
\hline Geometric model & Discrete spool openings $\phi=10^{\circ}$ to $90^{\circ}$ with $5^{\circ}$ step \\
\hline Fluid model & 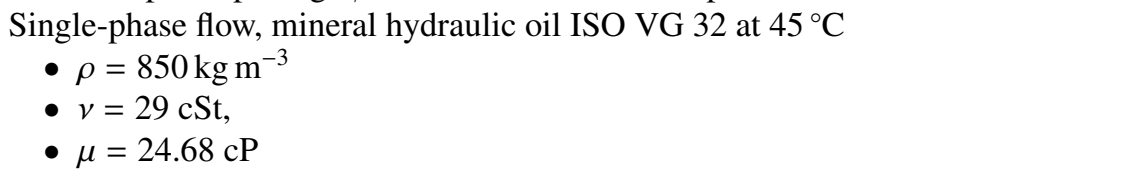 \\
\hline Mesh & $\begin{array}{l}\text { Adaptive finite volume discretization, rectangular parallelepipeds with initial } \\
\text { maximum size } 0.8 \mathrm{~mm} \text {, number of cells } \approx 1.1 \text { million }\end{array}$ \\
\hline Turbulence model & $k-\varepsilon$ turbulence model \\
\hline \multirow[t]{4}{*}{ Boundary conditions } & Metering characteristic \\
\hline & $\begin{array}{l}\text { Static pressure at the inlet and the outlet: } \\
-p_{\text {in }}=0.35 \mathrm{MPa}, 0.6 \mathrm{MPa} \text { and } 1.1 \mathrm{MPa} \\
-p_{\text {out }}=0.1 \mathrm{MPa}\end{array}$ \\
\hline & Power loss characteristic: \\
\hline & $\begin{array}{l}\text { Volume flow rates across the RTSV: } \\
\text { - } Q=25 \mathrm{~L} \mathrm{~min}^{-1} \text { to } 275 \mathrm{~L} \mathrm{~min}^{-1} \text { with the } 25 \mathrm{~L} \mathrm{~min}^{-1} \text { increment } \\
\text { Other simulation conditions: } \\
\text { - No-slip, smooth, adiabatic wall } \\
\text { - Two-scale wall function } \\
\text { - Turbulence intensity } 2 \% \\
\text { - Turbulence length } 0.1 \mathrm{~mm} \\
\text { - Leakages in clearances are neglected }\end{array}$ \\
\hline
\end{tabular}

Table 1: Preprocessing settings of the CFD modelling.

position of the spool $\phi$ was added as the geometrical 400 parameter varying from $10^{\circ}$ to full open state of $90^{\circ}{ }_{401}$ with a $5^{\circ}$ step.

Secondly, the pressure loss $p_{\text {loss }}$ was modeled by varying a valve inlet volume flow rate within a range $Q 25 \mathrm{Lmin}^{-1}$ to $275 \mathrm{Lmin}^{-1}$ coupled with the invariant static outlet pressure of $p_{\text {out }}=0.1 \mathrm{MPa}$ and the varying opening angle $\phi$. The boundary conditions at the inlet 406 and outlet also included the turbulent quantities, which 407 in this study were the turbulence intensity of $2 \%$ and 408 the turbulence length scale, the hydraulic diameter of 409 the inlet and outlet.

\subsection{Oil model}

The oil used in the CFD study is the petroleum-based ${ }_{413}$ anti-wear hydraulic mineral oil, viscosity grade 32 . It ${ }_{414}$ has been treated as a compressible fluid, i.e. viscosity- 415 and density-temperature functions were used by the 416 FloEFD solver, although the temperature increase has been proven to be local in small areas next to the throttling edges [31].

The temperature field in the fluid subdomain is non-uniform. equal to $45^{\circ} \mathrm{C}$ that corresponded to normal operational conditions of fluid power systems as well as intended test conditions. Oil properties correlating to this value of oil temperature [32] as well as other preprocessing settings of the CFD model are summarized in table 1

\subsection{Modelling results}

\subsubsection{Metering characteristic}

During the CFD simulation studies of the valve, the spool angular position is considered as the main geometric parameter ranging from $\phi=10^{\circ}$ to $90^{\circ}$ with an increment of $5^{\circ}$. The pressure drop across the orifice had definite values of $\Delta p=0.25 \mathrm{MPa}, 0.5 \mathrm{MPa}$ and $1 \mathrm{MPa}$. The volume flow rate $Q_{C F D}(\phi)$ as a function of the spool position has been simulated for the specified pressure drops. Interpolated plots for discrete data points of CFD calculated flow rates are illustrated in fig. 7

The CFD simulated volume flow rate $Q_{C F D}$ increases non linearly as the orifice area grows. From $\phi=25^{\circ}$ to $60^{\circ}$ of the spool angular position the volume flow rate exhibits steeper rise comparing with the regions of extreme spool positions. According to the simulated 


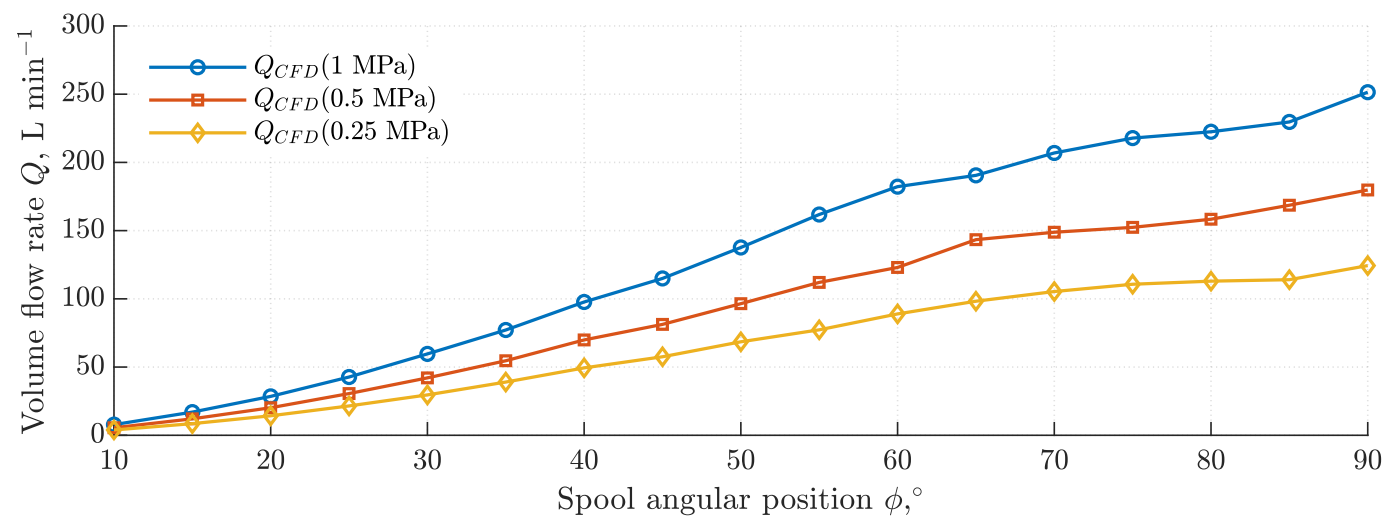

Figure 7: Modelled metering characteristic $Q(\phi)$ at $\Delta p=0.25 ; 0.5 ; 1 \mathrm{MPa}$

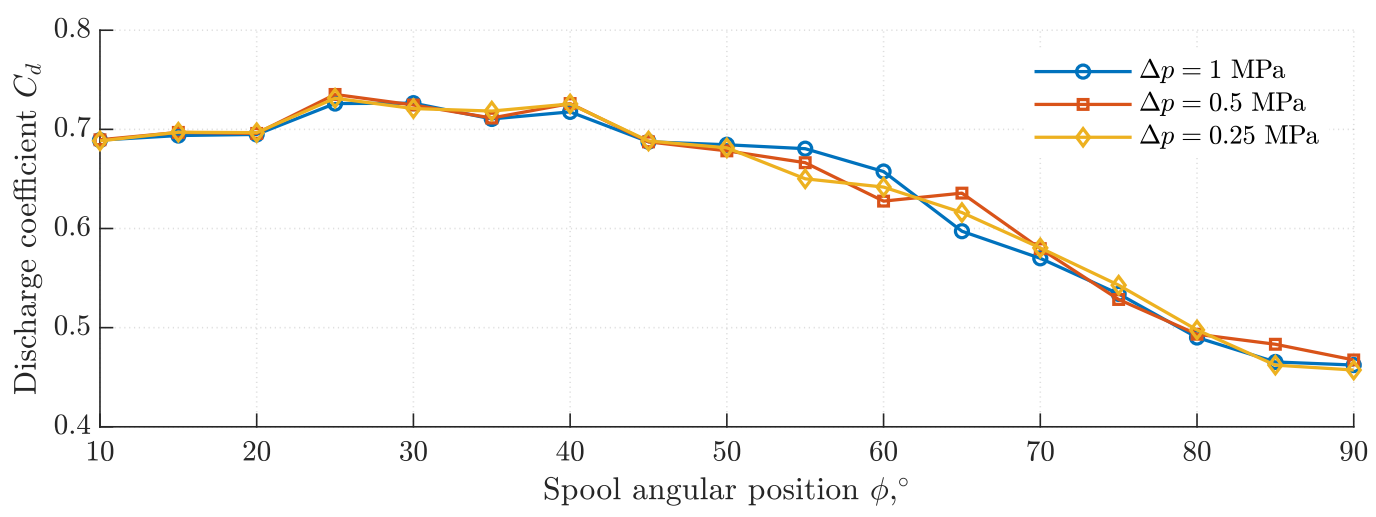

Figure 8: Discharge coefficient $C_{d}(\phi)$ at $\Delta p=0.25 ; 0.5 ; 1 \mathrm{MPa}$

results, domains close to the maximum and minimum ${ }^{437}$ spool positions have more gradual flow rate gains. This 438 benefits controllability of a hydraulic actuator at small ${ }_{439}$ and maximum speed regimes.

\subsubsection{Discharge coefficient}

Simulated flow rate characteristic $Q_{C F D}$ of the valve has ${ }^{442}$ allowed calculation of the discharge coefficient of the ${ }^{443}$ orifice for any given spool angular position according ${ }_{444}$ to the Bernoulli equation.

$$
C_{d}(\phi)=\frac{Q_{C F D}}{A(\phi)} \sqrt{\frac{\rho}{2 \Delta p}}
$$

For every pressure drop across the valve, computed discharge coefficient curves in fig. 8 follow the same trend and effectively coincide. Regardless of the imposed pressure differentials, discharge coefficient curves decrease as the valve opens. The maximum value 450 of the coefficient is $C_{\text {d.max }}=0.735$ at $\phi=25^{\circ}$, the ${ }_{451}$ minimal value is $C_{d \cdot \min }=0.457$ at the valve's open state, $\phi=90^{\circ}$. With the predetermined orifice area and the discharge coefficient relation, hydraulic behaviour of the valve can be predicted for any operational regime of the hydraulic system.

\subsubsection{Reynolds number}

To confirm the turbulent nature of an oil flow pattern in the valve for different spool angular positions, estimation of the Reynolds number $\mathrm{Re}$ has been performed according to the equations below:

$$
\operatorname{Re}=\frac{\rho V L}{\mu}=\frac{V L}{v}
$$

where $V$ and $L$ are characteristic velocity and length scales of the flow, $\rho, \mu$ and $v$ - fluid's density, dynamic and kinematic viscosity respectively, [33].

For circular conduits, the Reynolds number can be expressed through the volume flow rate $Q$, the flow area 


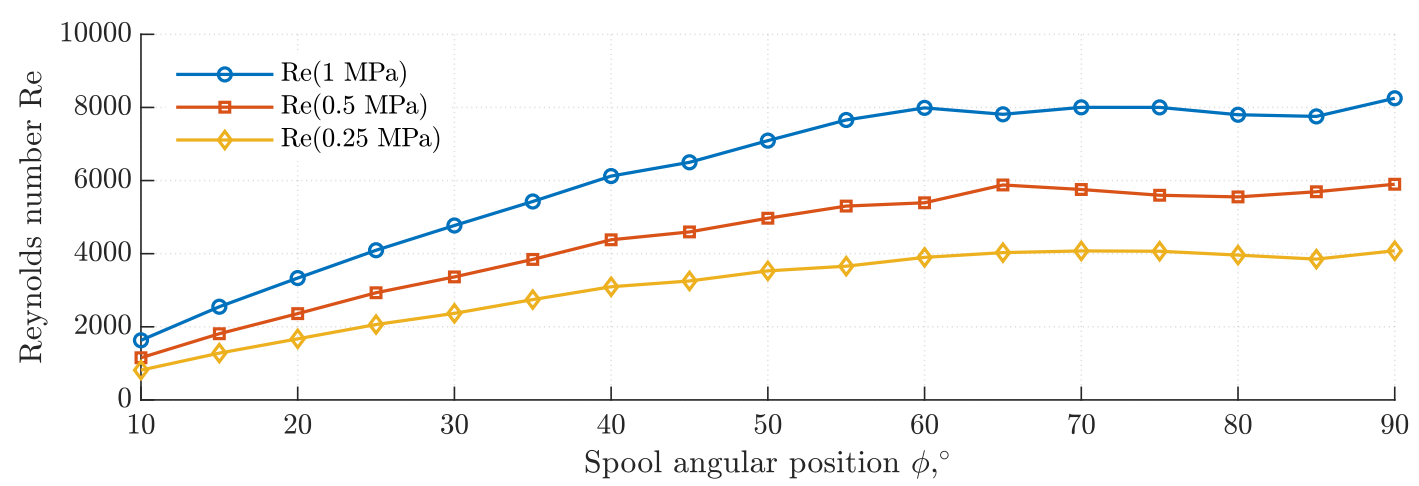

Figure 9: Reynolds number function $\operatorname{Re}(\Delta p, \phi)$

$A$ and the hydraulic diameter $D_{h}$, which is the same as ${ }_{481}$ the pipe diameter or the characteristic length $L,[34]$. 482 The more general formula for the hydraulic diameter, ${ }_{483}$ which accounts for noncircular pipes and hoses as the ${ }_{484}$ drop-shaped orifice, is

$$
D_{h}=\frac{4 A}{S}
$$

where $S$ is the perimeter of the flow cross-section. For the case of the initially chosen drop-shaped orifices, the total orifice perimeter $S$ and area $A$ were measured. The results are demonstrated in figs. 3 and 4 respectively. Therefore, it was possible to calculate the hydraulic diameter $D_{h}$ of the orifice and use it further to estimate the Reynolds number.

The formula used for Reynolds number estimation is derived from eq. (15) through the hydraulic diameter $D_{h}$ in eq. $(16)$, the volume flow rate $Q$ passing through the area $A$.

$$
\operatorname{Re}=\frac{Q D_{h}}{A v}
$$

The results of the Reynolds number calculations for ${ }_{498}$ different pressure differentials $\Delta p$ and spool angular ${ }_{499}$ positions $\phi$ are illustrated in fig. 9 The figure confirms, 500 that for considered values of the valve opening and ${ }_{501}$ the pressure differential, the valve operates with the ${ }_{502}$ turbulent flow pattern since the Reynolds number exceeds the critical value of 2300 at almost all simulated design points.

It also can be concluded, that in the range of small valve 504 openings, when the spool is positioned at $\phi<30^{\circ}$, the ${ }_{505}$ flow can take transitional nature in the throttling orifice ${ }_{506}$ areas as in this band the Reynolds number is within 507 $1000<\operatorname{Re}<4800$

\subsubsection{Pressure losses}

In order to estimate the pressure loss $p_{\text {loss }}$ imposed by the valve on the hydraulic circuit that the valve had been installed into, the volume flow rate $Q$ passing through the valve and the outlet pressure of $0.1 \mathrm{MPa}$ were selected as the hydraulic boundary conditions. The volume flow rate varied in a range $Q=25 \mathrm{~L} \mathrm{~min}^{-1}$ to $275 \mathrm{~L} \mathrm{~min}^{-1}$. The spool angular position ranges as $\phi=$ $40^{\circ}$ to $90^{\circ}$. The measured goal is the magnitude of inlet pressure $p_{i n}$. Hence, the pressure loss is defined by the difference

$$
p_{\text {loss }}=p_{\text {in }}-p_{\text {out }} .
$$

492 The resultant pressure loss curves, i.e. $p_{\text {loss }}(Q)$ at $\phi=$ const, for specified flow rates increase nonlinearly, with the dependency close to exponential. The maximum $p_{\text {loss }}$ does not exceed $1 \mathrm{MPa}$ at the fully open state of the valve and the maximum flow rate through it, i.e. at $Q\left(\phi_{\max }\right)$, see fig. 10

$$
P_{\text {loss }}=p_{\text {loss }} Q .
$$

The obtained pressure loss function $p_{\text {loss }}(Q)$ allows further calculation of the power losses due throttling, see fig. 11. according to the formula below. This power is dissipated through oil viscous friction and increases the internal energy of the oil [1].

\section{Experimental study}

A prototype of the valve was manufactured in order to test and validate the theoretical model of the valve described above. A detailed experimental procedure is designed to test the behaviour of the valve within the hydraulic system and test its modelling characteristics. 


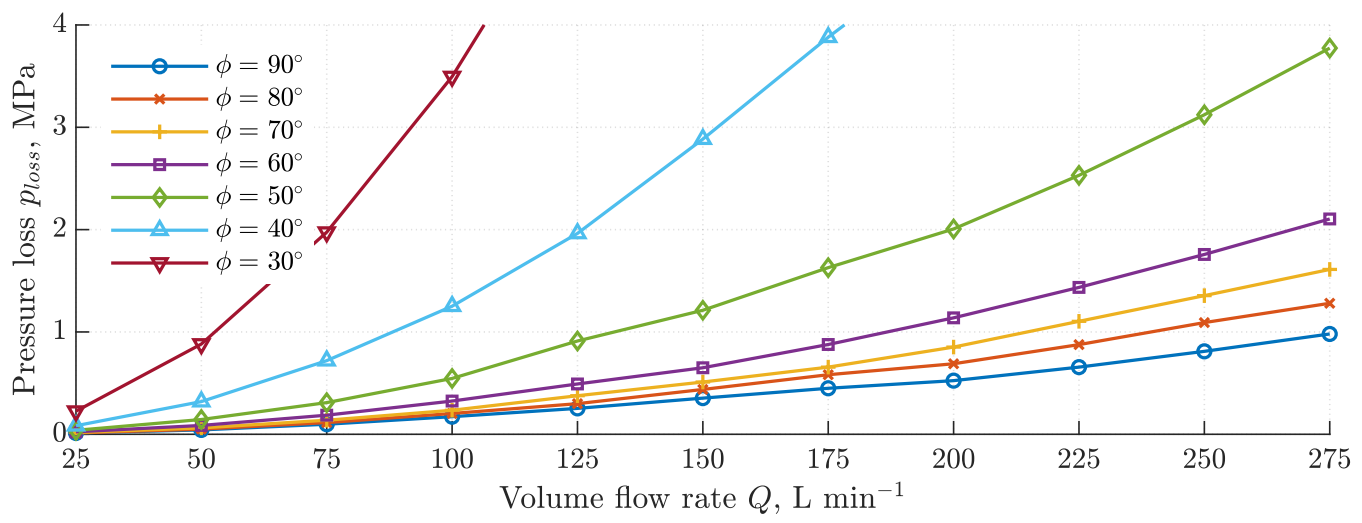

Figure 10: Modelled pressure losses $p_{\text {loss }}(Q)$ at $\phi=$ const.

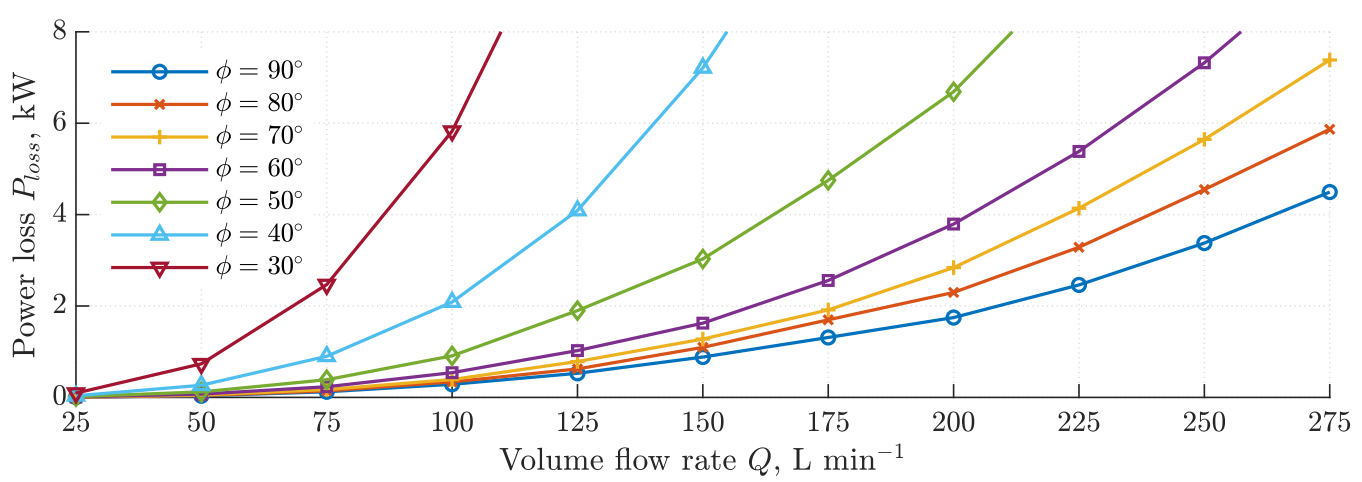

Figure 11: Modelled power losses $P_{\text {loss }}(Q)$ at $\phi=$ const.



Figure 12: The block scheme of the data acquisition system. Blocks and signals colors correspond to: black - mechanical, blue - hydraulic, red electric. 


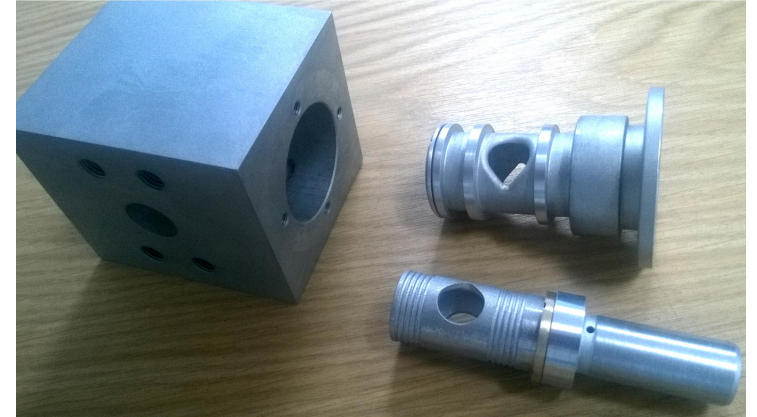

Figure 13: The main manufactured parts of the prototype valve: the valve body, the guiding sleeve inside the main sleeve, the spool with the thrust bearing on it.

\subsection{Prototype valve}

A physical prototype of the valve was manufactured by a contractor and assembled in accordance with the design specification described in section 2. The prototype valve comprised original, standard and "off-the-shelf" parts.

Original parts include the RTSV's mechanical parts required to execute the new throttling method. These were manufactured in accordance with the design described above, see fig. 13

However, a few geometrical simplifications of the valve parts were applied. Although the valve body's collecting channel in the prototype had a rectangular cross-section area $A_{a n}$, the area was kept the same as in the original design specification, where the channel's shape corresponds to the one illustrated in fig. 1. Transition from the collecting channel to the outlet hydraulic port did not have a fillet on it. These deviations were considered as negligible and not influencing the overall valve performance. The overall length of the body was slightly shortened to reduce amount of the needed material. This resulted in small offset in the mounting threaded holes, which was taken into account during designing of the mounting base plate assembly described below.

\subsection{Data acquisition system}

The experimental data acquisition system (DAS) was used to collect data about the behaviour of the new valve in physical environment, as a part of a hydraulic system. The main purpose of the used DAS is to enable safe collection of the test data since the main component of the hydraulic is the mineral oil under high pressure.

DAS can be divided into three parts according to the physical nature of transmitted signals, see fig. 12 . The mechanical component was described in the preceding sections. The details of the hydraulic test bench are discussed in the following section. Depending on the characteristic of interest, the monitored and controlled variables varied. Exact sets of monitored and controlled variable are summarized in the following experiment description.

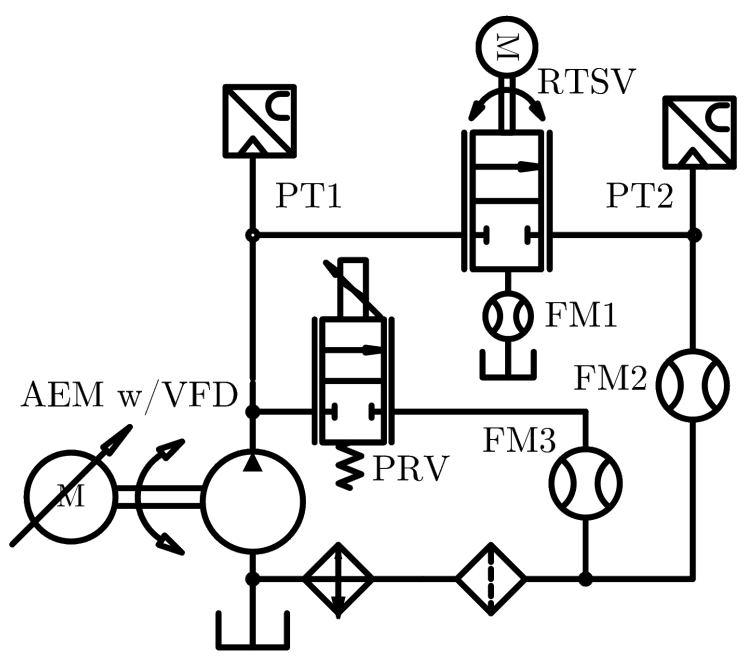

Figure 14: The scheme of the hydraulic test rig.

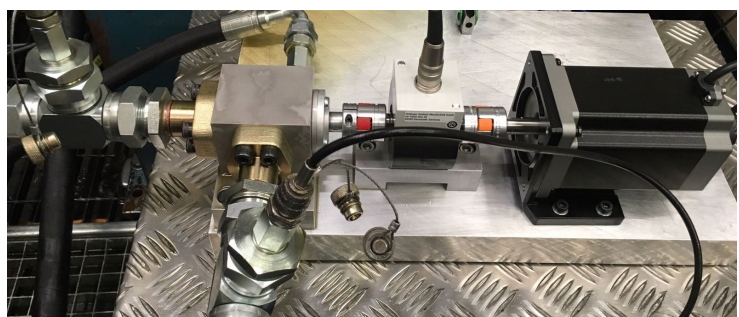

(a) The prototype valve, the RTSV.

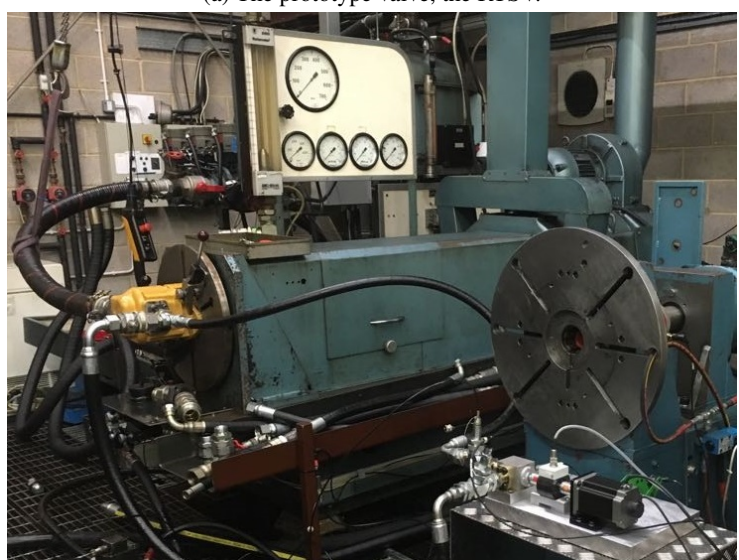

(b) The hydraulic test rig.

Figure 15: The photos of the used hydraulic test rig. 


\begin{tabular}{|c|c|c|c|c|}
\hline Instrument & Make & Model & Range & Accuracy \\
\hline Pump & Hydreco & QR6 6160 & $\begin{array}{l}\text { Displacement } 160 \mathrm{~cm}^{3} \mathrm{rev}^{-1} \\
\text { Speed } 450 \mathrm{rev} \mathrm{min}^{-1} \text { to } 2750 \mathrm{rev} \mathrm{min}^{-1}\end{array}$ & \\
\hline FM & Kracht & $\mathrm{VC} 12$ & 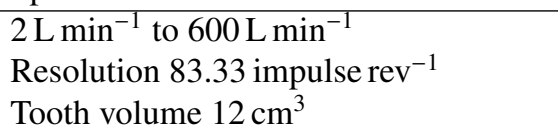 & $\pm 0.3 \%$ \\
\hline PT & Gems & 3100B0400 & $\begin{array}{l}400 \text { bar } \\
\text { Output } 0.5 \mathrm{~V} \text { to } 4.5 \mathrm{~V} 4 \mathrm{~mA} \text { to } 20 \mathrm{~mA}\end{array}$ & $\pm 0.25 \%$ \\
\hline TT & HBM & T20WN & $\begin{array}{l}10 \mathrm{Nm} \\
\text { Output } \pm 5 \mathrm{~V} 10 \mathrm{~mA} \pm 8 \mathrm{~mA}\end{array}$ & $\pm 0.5 \%$ \\
\hline SM & Oriental Motors & RKS5913R & $0.72^{\circ}$ step & $\pm 0.05^{\circ}$ \\
\hline
\end{tabular}

Table 2: Instrumentation.

\subsubsection{Hydraulic test rig}

Figure 14 shows the scheme of the hydraulic test setup 587 used for the experiments. It can be divided on the 588 power, oil conditioning subsystems, sensors and the test 589 prototype valve, RTSV. Figure $15 \mathrm{a}$ shows specifically 590 the prototype valve, RTSV, and fig. $15 \mathrm{~b}$ illustrates the general view on the used test rig.

The oil storing and conditioning subsystem included an 592 oil tank with an inbuilt heater, oil filters, and an air blast ${ }^{593}$ heat exchanger. The tank also comprised a breather 594 that connected the tank's chamber to surrounding 595 environment to ensure that the atmospheric pressure ${ }^{596}$ level was maintained in the tank and the return line of ${ }^{597}$ the hydraulic system.

The power subsystem of the test rig was equipped with an asynchronous electric motor (AEM) with a variable frequency drive (VFD). The AEM served as a pump's 601 driver, while the VFD allowed to set the rotational speed 602 of the pump's shaft and, hence, to control the pump's ${ }^{603}$ volume flow rate supplied into the hydraulic system. ${ }^{604}$ The pump used here was a Hydreco's spur gear pump ${ }^{605}$ QR6 series with displacement of $160 \mathrm{~cm}^{3} \mathrm{rev}^{-1}$, see the ${ }^{606}$ yellow-painted element in fig. $15 \mathrm{~b}$ Its operating speed ${ }^{607}$

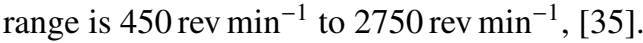

In the power subsystem, in parallel to the pump, the was a pressure relief valve (PRV), which was installed in the by-pass line. The PRV is electronically controlled ${ }^{611}$ proportional valve, which allowed to set the valve's inlet ${ }^{612}$ pressure to the desired value. It also limited the pressure ${ }^{613}$ level in the hydraulic system, implementing the safety ${ }^{614}$ function. The by-pass line also included the flow meter ${ }^{615}$ FM3 to monitor the amount of flow passing through 616 this line. The main hydraulic line incorporated the test ${ }^{617}$ valve, RTSV. The drain line of the RTSV featured the ${ }_{618}$ flow meter FM1 to measure the internal leak through ${ }_{619}$ the valve's parts. Up- and downstream to the prototype ${ }_{620}$ valve, two pressure transducers were mounted PT1 and PT2 respectively. Additionally, the flow meter FM2 was installed in the downstream of the test line to enable measuring the volume flow rate passing through the test valve.

\subsubsection{Instrumentation}

The oil's supply subsystem allowed keeping the temperature level constant in time. Thermocouples, the air-blast oil cooler and the heater formed the closed-loop temperature control system. The tank-embedded thermocouples serving as temperature sensors allowed setting the temperature level on the same level throughout the length of an experiment. The working fluid was a zinc and chlorine free anti-wear hydraulic oil, Shell Tellus S2 V32 [36].

To monitor volume flow rates circulating the hydraulic system, three gear-type flow meters FM1, FM2 and FM3 were installed in the following hydraulic lines: pumps's by-pass, test valve's line and valve's internal leakage line. The latter enabled measurement of the oil spillage from the valve's central chamber, through the spool-sleeve gap and the thrust bearing to the tank. The leak drain line allows to lubricate all mechanical contacts within the valve with the working fluid, collect the leakage flow and direct it to the tank, see fig. 1

The flow meters included two non-contacting measuring gears, which were driven by the liquid flow on a principle of a gear pump [37]. The pressure transducers were used to collect the data related to static pressure. The pressure transducers feature a sputter diaphragm, deformation of which is sensed and transformed into the pressure signal [38].

The used instrumentation is summarized in table 2. According to the sensors' datasheets, accuracy of the used transducers can ensure low systematic errors. 


\begin{tabular}{rllll}
\hline Test & Variable & Type & Instrument & Range \\
\hline \multirow{3}{*}{$Q(\phi)$} & $p_{\text {in }}$ & Controlled & VFD, PRV & $0.35 \mathrm{MPa}$ to $1.1 \mathrm{MPa}$ \\
at $\Delta p=$ const & $\phi$ & Controlled & SM & $30^{\circ}$ to $90^{\circ}$ \\
& $p_{\text {out }}$ & Monitored & PT2 & $40 \mathrm{MPa}$, see table 2 \\
& $Q$ & Monitored & FM2 & $600 \mathrm{Lmin}^{-1}$, see table 2 \\
\hline \multirow{3}{*}{$\Delta p(Q)$} & $Q$ & Controlled & VFD, PRV & $25 \mathrm{~L} \mathrm{~min}^{-1}$ to $175 \mathrm{~L} \mathrm{~min}^{-1}$ \\
at $\phi=$ const & $\phi$ & Controlled & SM & $50^{\circ}$ to $90^{\circ}$ \\
& $p_{\text {in }}$ & Monitored & PT1 & $40 \mathrm{MPa}$, see table 2 \\
& $p_{\text {out }}$ & Monitored & PT2 & $40 \mathrm{MPa}$, see table 2 \\
\hline
\end{tabular}

Table 3: Test plan.

\subsection{Test procedures}

The general goal during the design of the experiment stage was to replicate the valve metering characteristics 659 obtained in the modelled environment. Test procedure 660 development consisted of selecting and dividing the 661 variables into controlled and recorded in order to enable 662 recreation of the metering characteristics and pressure ${ }_{663}$ losses. The ranges of controlled variables corresponds 664 to the boundary conditions used in the CFD parametric 665 simulations for a particular metering function. The 666 summary of the test procedure is listed in table 3 During all tests the oil temperature was kept constant at $45^{\circ} \mathrm{C}$.

\subsection{Tests results}

The following sections report the results of the 672 experiments conducted as a part of this investigation. 673 The data collection was performed in according to the 674 test plan, see table 3 The figures shown below are the results of the static hydraulic representation of the 675 proposed rotary flow control valve.

As a general note, visual inspection of the valve before, 677 during and after each test did not reveal any leakages 678 or visible deformations of the valve's parts. There 679 were also no signs of rubber O-rings extrusions. The 680 inspection allowed to conclude, that the valve was able 681 to withstand highly pressurized oil without leakages and 682 failure to operate. Therefore, the general design of 683 the prototype was considered satisfactory and able to 684 performs its functions.

\subsubsection{Metering characteristic}

During measurements of the volume flow rate 688 characteristic of the valve $Q(\phi)$, the spool angular 689 position was ranging from $\phi=30^{\circ}$ to $90^{\circ}$. At every 690 spool position $\phi$, the PRV and the VFD were used to 691 set the pressure differential across the valve equal to the ${ }_{692}$ values of $\Delta p=0.25 \mathrm{MPa}, 0.5 \mathrm{MPa}$ and $1 \mathrm{MPa}$. Then, 693 the readings from the flow meter on the main line were recorded.

Experimental graphs of the volume flow rate as a function of the spool angular position are shown in fig. 16. These follow the same trend as the CFD modelled one, see fig. 7 However, the magnitudes differ drastically, especially for small valve openings and the low-opening spool positions, i.e. up to $\phi=30^{\circ}$, see fig. 17 showing the error between simulated and measured data.

According to fig. 17, the predicted values of the volume flow rate exceed the measured values by $48.75 \%$, $51.77 \%$ and $55.85 \%$ in average for the three pressure drops of $1 \mathrm{MPa}, 0.5 \mathrm{MPa}$ and $0.25 \mathrm{MPa}$ respectively. The error between the measured, see fig. 16 and modelled, see fig. 7, volume flow rates does not depend on the pressure drop causing the flow. That testifies to consistent data collection.

\subsubsection{Pressure losses}

During measurements of the pressure losses, VFD and PRV were simultaneously used to control the pump's discharge volume flow rate and the valve's inlet pressure respectively. The spool was put in the predetermined position in the range $\phi=50^{\circ}$ to $90^{\circ}$ according to the test procedure. The spool openings below $\phi=50^{\circ}$ caused the inlet pressure to rise above $20 \mathrm{MPa}$, which was considered unsafe. The parameters monitored were the valve's outlet and inlet pressure levels. The difference between these values constituted the predicted pressure drop $\Delta p$, or the pressure loss.

The opposite tendency to the volume flow rate results was observed to the pressure drop curves. Here, the experimental values are higher than the modelled with a higher similar margin. The pressure measurements were performed with the maximum volume flow rate $175 \mathrm{~L} \mathrm{~min}^{-1}$. Further increase in the volume flow rate led to the inlet pressure level rise above $20 \mathrm{MPa}$, which 


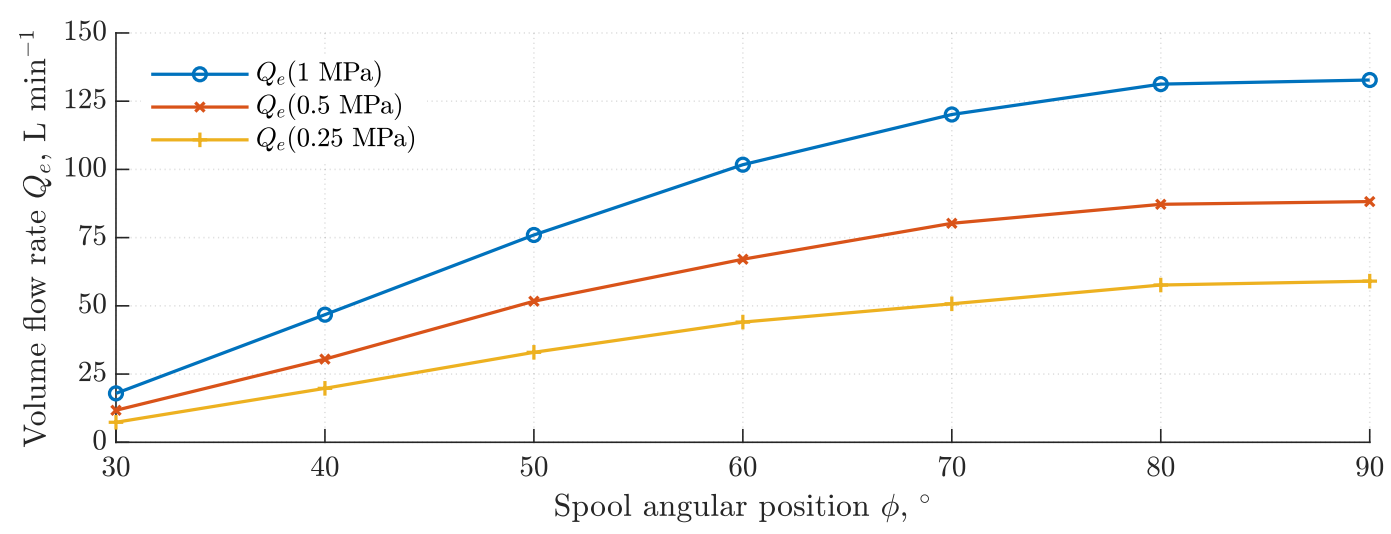

Figure 16: Tested metering characteristic $Q_{e}(\phi)$ at $\Delta p=0.25 ; 0.5 ; 1 \mathrm{MPa}$

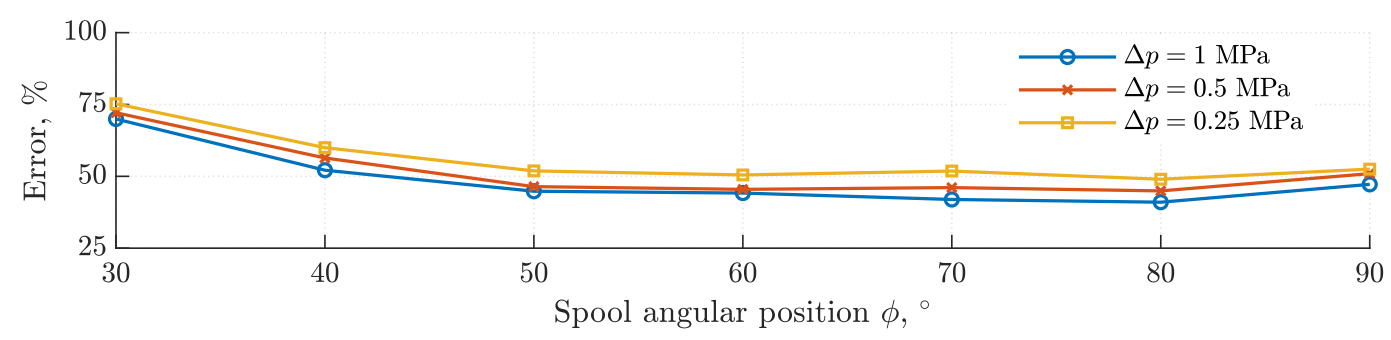

Figure 17: Percentage difference between simulated and tested metering characteristic $Q(\phi)$ at $\Delta p=0.25 ; 0.5 ; 1 \mathrm{MPa}$

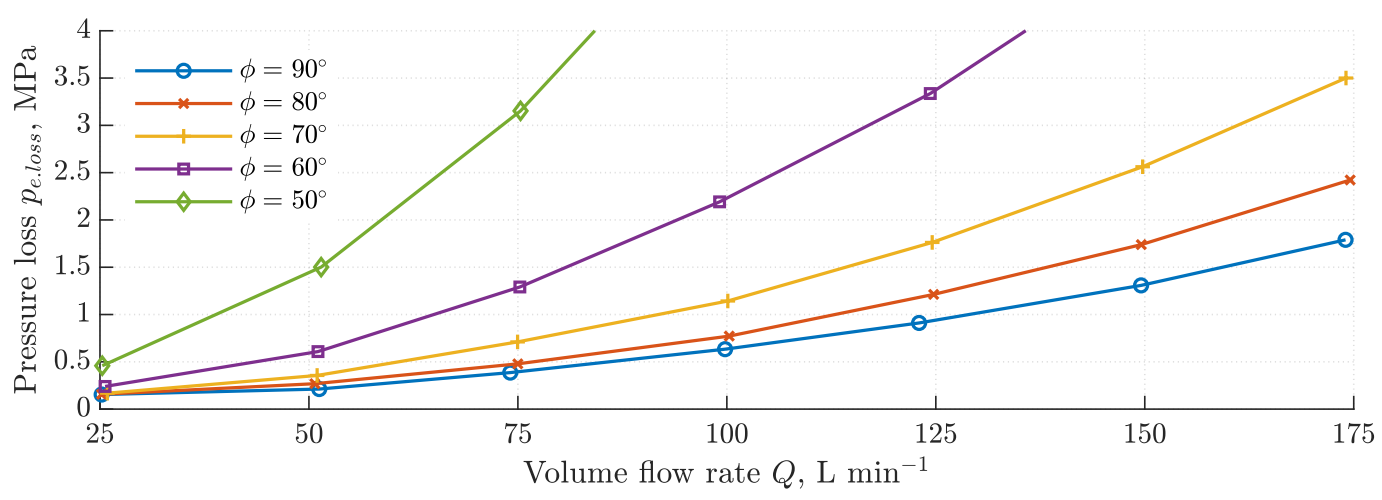

Figure 18: Tested pressure loss $p_{\text {e.loss }}$ at $\phi=$ const.

was considered risky in terms of structural integrity of 704 the valve.

In case of pressure drop measurements, the simulated ${ }^{700}$ results, see fig. 10, and the test results, see fig. 18, ${ }^{70}$ differ, see the percentage differences between the two for certain valve openings in fig. 19. The smaller valve openings result in the highest results error of $90.25 \% 709$ on average, i.e. in these cases experimental results are almost two times bigger than simulated, regardless of 711 volume flow rate.
As the opening reaches maximum, the error decreases reaching $72.69 \%$ in the range of volume flow rates from $100 \mathrm{~L} \mathrm{~min}^{-1}$ to $150 \mathrm{~L} \mathrm{~min}^{-1}$. At the fully open state and the minimal volume flow rate, the error is comparable with small opening's errors, i.e. $91.68 \%$.

\subsubsection{Correlation with modelling}

According to figs. 17 and 19, the used simulation model overestimates the performance characteristics of the physical prototype valve for both the volume flow 


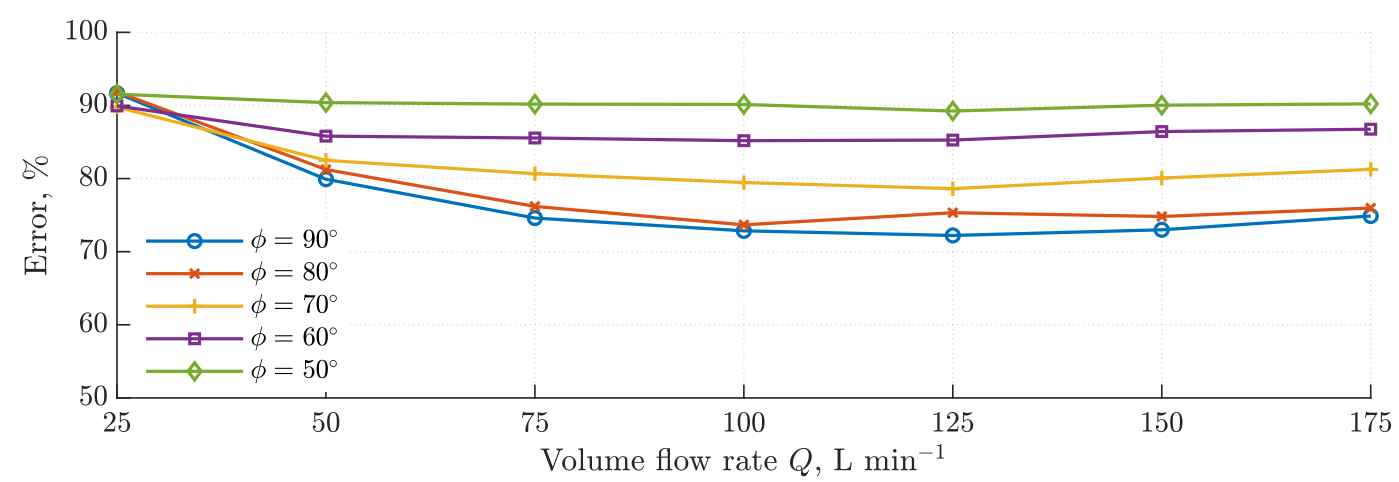

Figure 19: Percentage difference between modelled and tested pressure drops $\Delta p(Q)$ at $\phi=$ const.

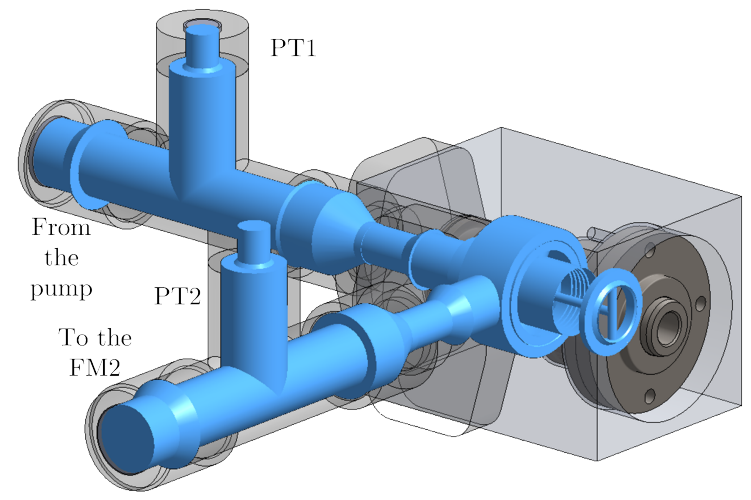

Figure 20: Corrected geometric model and fluid sub domain.

rate and the pressure drop curves. For the pressure 749 drop the deviation reaches on average $82.78 \%$, see 750 fig. 19. Nevertheless, general trends of the simulated and experimental results conform. In particular, the monotonous increase of the volume flow rate with valve opening for different values of constant pressure drops was observed, see figs. 7 and 16 for the simulated and experimental flow rate curves respectively. The pressure drops for a set value of the valve opening were raising with a volume flow rate growth, see fig. 10 for the numerical results and fig. 18 for the experimental.

Several factors were identified, which were causing 759 such large errors. One factor affecting all measurements 760 and all performed tests was related to the accuracy 761 of the spool angular positioning. The prototype was 762 assembled in a way that overlap angles at the closed 763 state were impossible to measure and control. Hence, 764 although the valve was closed, the exact lengths of the 765 leak channels were hard to establish. Therefore, it was 766 challenging to ensure that leak channels' lengths are 767 equal to those used in the modelling stage. As a result, 768 the actual "zero" position differed from the simulated. In addition, a signal noise caused by the high variability of the flow parameters in time and non-uniformity of the pump's flow rate also affects the quality of the collected data due to introduction of a random error.

However, the main reason of the tested and modelled results differences can be attributed to the imperfections of the geometric model used. Firstly, it did not include fittings into the model's geometry. These fittings connect the pressure transducers and the prototype valve to the hydraulic system. Their internal passages were non-uniform in a cross-section, their routes were not straight. Hence, their internal passages created additional disturbances to the flow, which were not accounted in the simulation model. This is the first factor causing a divergence of the modelled and experimental valve's metering characteristics.

Moreover, the simulated geometric model did not take into account surfaces roughness of mechanical parts wetted with oil. Surface's roughness creates additional pressure losses due to viscous and boundary layer-surface friction. Together, these two factors can explain the difference between experimental and simulated results. To test these assumptions, additional modelling was performed.

\subsubsection{Corrected model}

To test the assumptions made, an extra run of the hydraulic behaviour modelling was performed. In this simulation the geometric model was corrected to include the instrumentation's fittings, pressure transducers' ports and adapters, which served as transition from one internal nominal diameter to another, see fig. 20. These elements were created with the internal geometry as close as possible to those used in testing. 


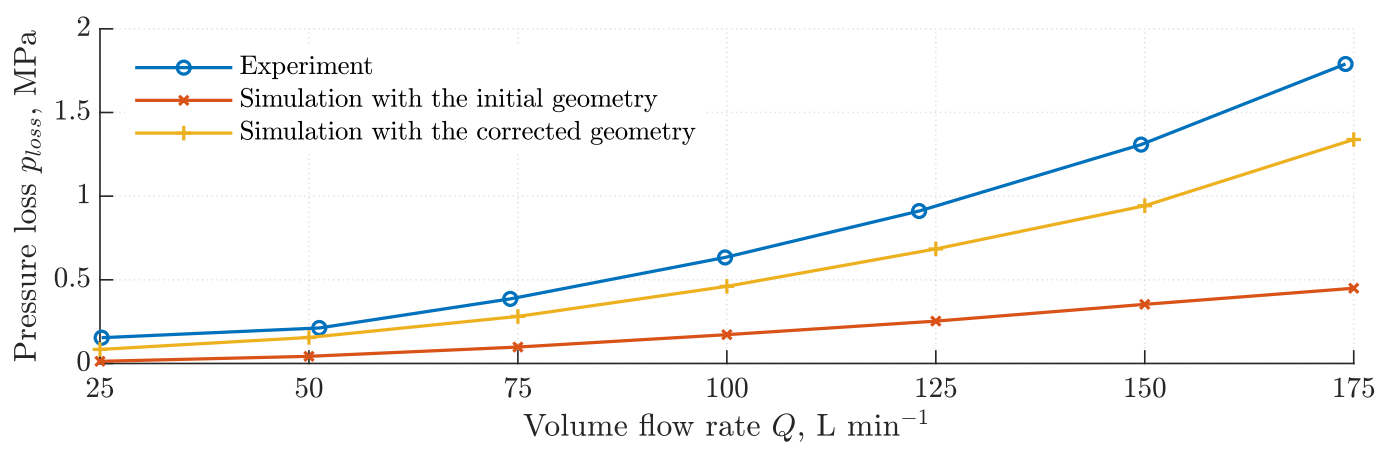

Figure 21: Correlation of study results for $\phi=90^{\circ}$.

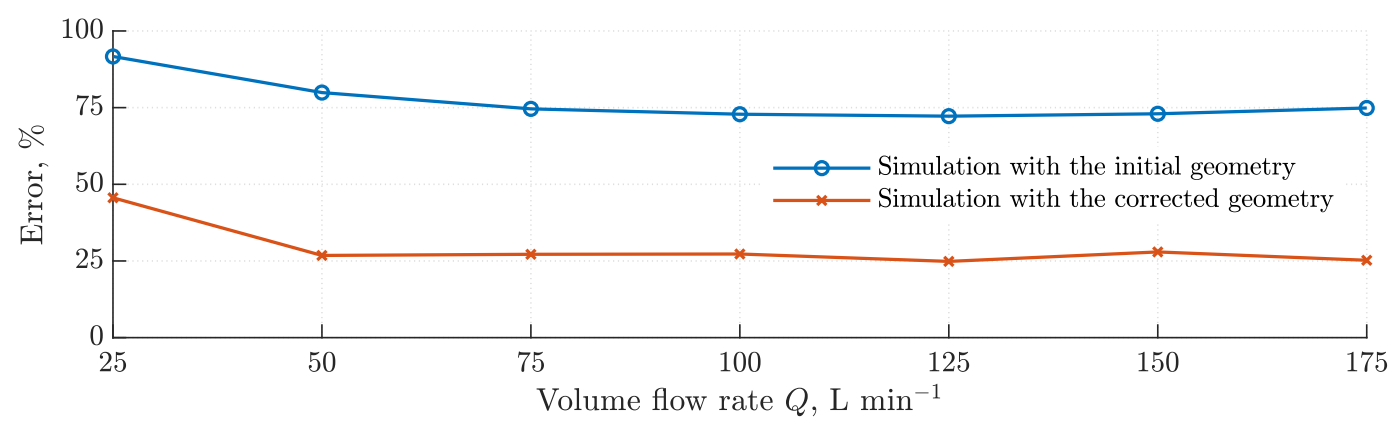

Figure 22: Percentage difference between simulated and test results of the pressure drop at $\phi=90^{\circ}$ relatively to the experiment data after inclusion of the test rig elements.

To fully replicate the geometry of the tested prototype, 792 the solid model of the valve has been modified as 793 well. In the manufactured prototype the annular collecting channel had a rectangular shape without fillets. Similarly the spool and sleeve orifices in the test valve had right edges, with no fillets. According to these deviations of the valve internal geometry from the design specification, modifications of the body, the sleeve and the spool were introduced. Adopted geometrical corrections resulted in the modified flow path, which reflected the test conditions more accurately.

Furthermore, roughness of $\operatorname{Ra} 25$ was assigned to all internal surfaces and passages, which are in contact with oil. The chosen roughness corresponds to finishing levels of the manufacturing processes used during prototype production - metal cutting with rough finish

To study the influence of the corrected geometry on the ${ }_{809}$ pressure drop, the hydraulic problem with the following 810 boundary conditions was solved: the spool angular 811 position $\phi=90^{\circ}$, the volume flow rate range $Q=812$ $25 \mathrm{~L} \mathrm{~min}^{-1}$ to $175 \mathrm{~L} \mathrm{~min}^{-1}$ and the the outlet static 813 pressure $p_{\text {out }}=0.101325 \mathrm{MPa}$, the measured variable 814 is the inlet pressure $p_{i n}$. Then, the pressure difference $\Delta p$ was calculated and plotted, see fig. 21 .

According to fig. 21, correcting the geometric model of the prototype valve brought the simulation results much closer to the experiment results. Taken measures to modify simulations allowed to reduce the average error between modelling and experiment by $47.75 \%$, from $77.02 \%$ to $29.27 \%$, see fig. 22 Therefore, it can be concluded that the biggest factor contributing to the simulation and the experiment results deviations was caused by the incomplete geometric model and the "smooth wall" assumption.

After introduced modifications to the CFD settings (inclusion of the fittings to the valve geometric model and adding roughness to the internal surfaces), the percentage difference between the corrected simulation and the experimental results still remained quite large, average $29.27 \%$, see fig. 22 Despite this error, the applied simulation model can be considered accurate enough to predict hydraulic behaviour of the tested prototype valve. The simulation results from the previous chapters can be deemed valid too and used in further performance improvement, design optimization, 
etc. The obtained metering characteristics from CFD 861 modelling hold their relevance since they pertained to 862 the valve geometry only, excluding the elements of the 863 hydraulic test rig and used instrumentation.

\section{Benchmark}

As a benchmark valve, Tecnord's products were selected as the company is one of market leaders 869 in hydraulic components design and production. 870 Moreover, Tecnord's manual rotary spool valves SJ-MRA [39] represent the closest analogue to the developed valve both structurally and in terms of specification.

According to the data sheet, the valve is a two ways, 875 two positions, proportional cartridge flow control valve 876 with a rotary, tubular spool, see fig. 23 It has a 877 cartridge-nest assembly method, the valve includes the 878 movable hollow spool inside the static sleeve as the main throttling pair. The outside diameter of the sleeve in this valve is determined by the thread 1" $5 / 16$, which corresponds to $32 \mathrm{~mm}$. The same outer sleeve diameter in the developed RTSV is $29.51 \mathrm{~mm}$. The spool has two orifices, which are located opposite to each other. Its nominal volume flow rate is $151 \mathrm{~L} \mathrm{~min}^{-1}$, the rated operational pressure is $20.7 \mathrm{MPa}$. Despite many similarities, the Tecnord's valve is manually driven, which substantially limits its ability for fine control and, hence, its application range.

According to the performance data of this valve, in the 888 fully open state at the rated flow rate of $150 \mathrm{~L} \mathrm{~min}^{-1}$ the 889 created pressure drop by the valve makes up $1.1 \mathrm{MPa} .890$ Whereas in the RTSV the corresponding pressure drop 891 constitutes $0.35 \mathrm{MPa}$, see fig. 10 , with $67.9 \%$ difference 892 relatively to the Tecnord's valve. In this comparison, the simulated data for the valve geometry without the elements belonging to the test rig instrumentation was used. The comparison results are illustrated in fig. 25 .

The calculated percentage of the average pressure drop 897 reduction of $71.66 \%$ can be directly translated into 898 the energy efficiency gain. Since the throttling power 899 loss is proportional to the pressure drop, the curve 900 in fig. 25 also corresponds to percentage of efficiency improvement relative to the Tecnord's reference valve.

\section{Discussion}

The performance evaluations during testing of the 906 new valve, referred as the Rotary Tubular-Spool Valve 907 (RTSV), allowed to validate the numerical models. The 908 simulated performance characteristics of the valve agree well with experiments. The metering and pressure loss functions were derived from CFD modelling and tested. Therefore, the models could be further used to analyse other aspects of RTSV's functionality.

The simulation results confirmed that the developed RTSV can successfully perform the required functions of a flow control valve in hydraulic systems and, thereby control the speed of an actuator or a rotary hydraulic motor.

Although the benchmark performance comparison study showed significant increase in energy efficiency of the new valve, it can differ for other valves designed by other manufacturers. Nevertheless, the obtained results confirm the potential of the new valve to become the industry standard, to replace single-spool valves with the independent metering arrangement of RTSVs to control the actuator's speed.

\section{Conclusion}

The objective of this research was met by investigating the three-dimensional fluid dynamics of internal flows within the valve to determine the initial metering characteristics and pressure losses it creates. The simulation results demonstrated RTSV's flow control feasibility as well as its ability to operate in the high-flow rate operational domain, with the volume flow rate reaching $250 \mathrm{~L} \mathrm{~min}^{-1}$ at $1 \mathrm{MPa}$ pressure differential. At the fully open state and the rated volume flow rate, valve's pressure drop was $0.81 \mathrm{MPa}$. Its performance was deemed comparable with industry available valves and having great potential to compete with benchmark hydraulic components.

The experimental investigation focused on characterising the RTSV's hydraulic performance. The prototype valve was built according to the suggested design concept. The test rig and the data acquisition system were designed, its elements were acquired and assembled. These enabled to replicate simulation set-up and to collect data pertaining to performance characteristics simulated before.

Manufacturing and testing of the prototype proved its relative design simplicity, promising functional performance, its strength and ease of manufacture and operation. The results of tests, although differing from initial simulations in average by $52.12 \%$ for the volume flow rate function and by $82.78 \%$ for pressure drops, followed same trends as the modelled. The factors causing the error were identified. To address these 

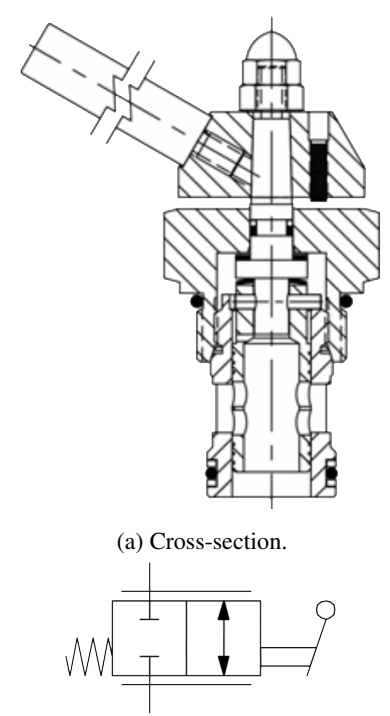

(b) Hydraulic symbol.

Figure 23: Tecnord's SJ-MRA rotary flow control valve, [39].
Flow (LPM)

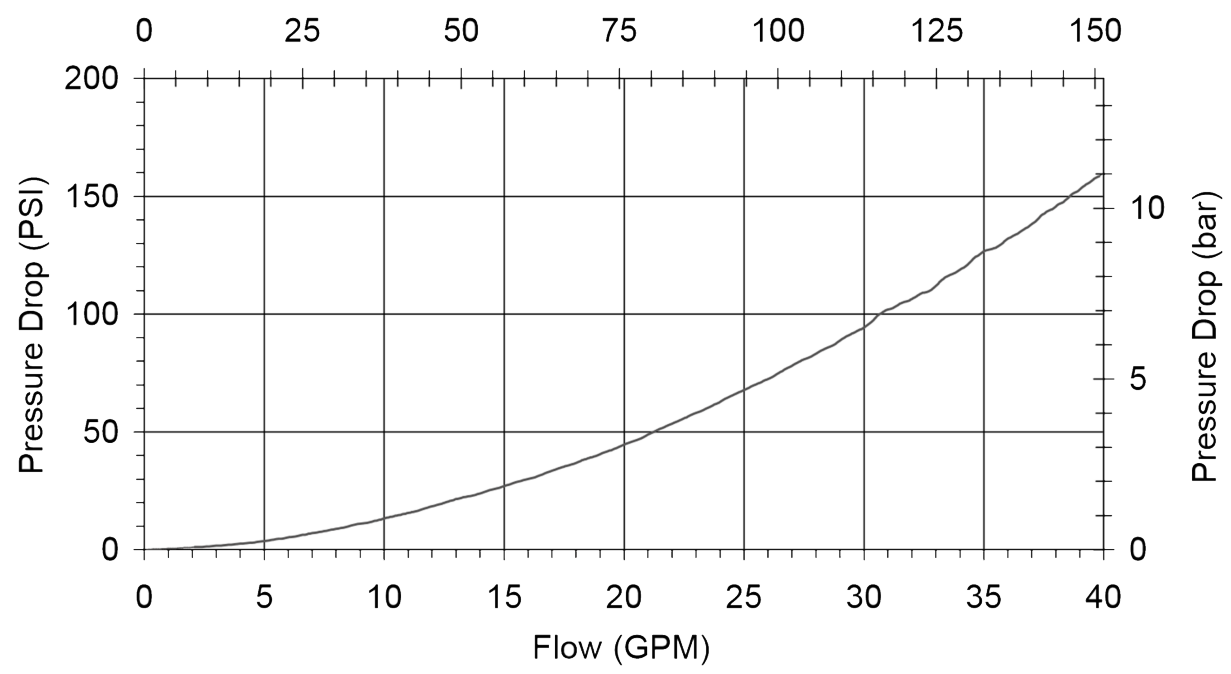

Figure 24: Test data of the pressure drop of SJ-MRA [39].

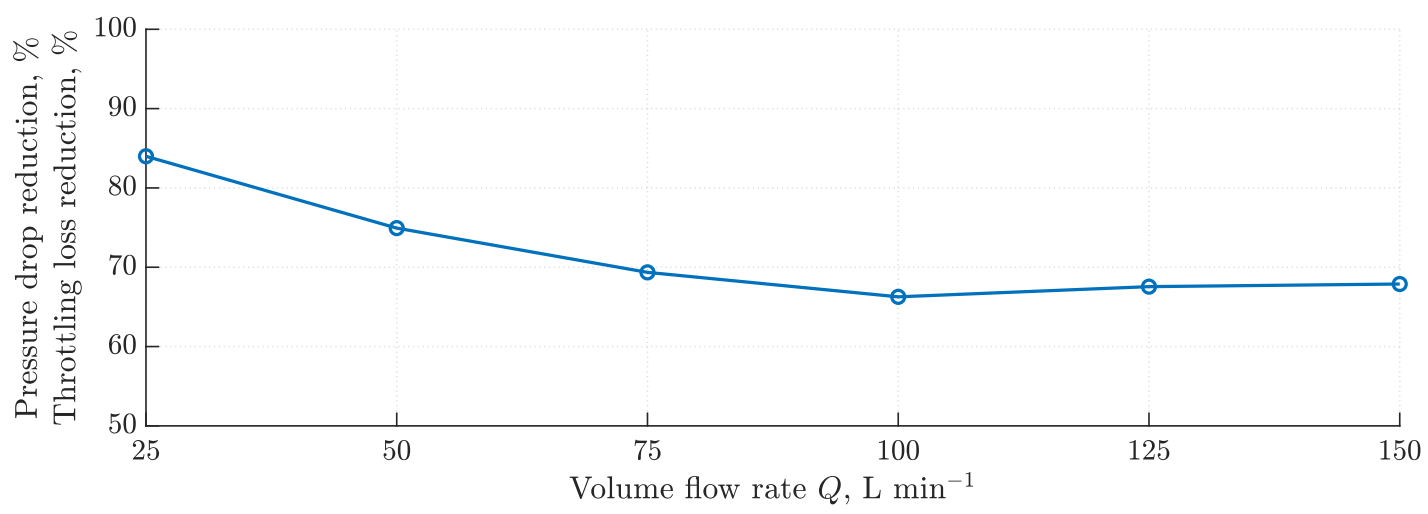

Figure 25: Throttling loss reduction in the RTSV relatively to the Tecnord's SJ-MRA.

factors, the CFD modelling settings were corrected. 923 the analogue valve.

These corrections to the model significantly reduced simulation/experiment errors in average by $47.75 \%$ for the pressure drop function. Thereby the initial 924 simulation results were validated.

The comparison study with the selected industrially ${ }^{926}$ available flow control valve having the similar structure ${ }_{928}^{927}$ and performance proved superior qualities of the 929 developed RTSV. The ability of the novel valve to ${ }^{930}$ improve energy efficiency of hydraulic control system ${ }_{931}^{931}$ was demonstrated and thereby confirmed by evaluating ${ }_{932}^{933}$ and comparing throttling losses occurring in the RTSV 934 and the reference valve. The average pressure drop ${ }^{935}$ reduction of the RTSV amounted to $71.66 \%$ relative to ${ }_{937}^{936}$

\section{References}

[1] Merritt, Herbert E., Hydraulic Control Systems, John Wiley \& Sons, Inc., New York, 1968.

[2] B. Eriksson, Mobile Fluid Power Systems Design with a Focus on Energy Efficiency, Doctoral dissertation, Linkopings University (2010).

[3] C. Burrows, Fluid power-some reflections, in: The 6th International Conference on Hydraulic Machinery and Hydrodynamics, no. February, Timisoara, Romania, 2004, pp. $51-56$.

[4] M. Axin, Mobile Working Hydraulic System Dynamics, Dissertation, Linköping University (2015).

[5] P. Tamburrano, A. Plummer, E. Distaso, R. Amirante, A review of direct drive proportional electrohydraulic spool valves: 
Industrial state-of-the-art and research advancements, Journal 1003 of Dynamic Systems, Measurement and Control, Transactions 1004 of the ASME 141 (2). doi:10.1115/1.4041063

[6] N. Herakovič, CFD simulation of flow force reduction in 1006 hydraulic valves, Tehnicki vjesnik - Technical Gazette 22 (2) 1007 (2015) 453-463. doi:10.17559/TV-20141128090939

[7] E. Lisowski, G. Filo, J. Rajda, Analysis of flow 1009 forces in the initial phase of throttle gap opening in 1010 a proportional control valve Flow Measurement and 1011 Instrumentation 59 (2018) 157 - 167. doi:https: 1012 //doi.org/10.1016/j.flowmeasinst.2017.12.011 URL http://www.sciencedirect.com/science/ 1014 article/pii/S095559861730331X

[8] E. Lisowski, W. Czyzycki, J. Rajda, Three dimensional CFD 1016 analysis and experimental test of flow force acting on the 1017 spool of solenoid operated directional control valve, Energy 1018 Conversion and Management 70 (2013) 220-229. doi:10. 1019 1016/j.enconman.2013.02.016

[9] M. Rabie, Fluid Power Engineering, McGraw-Hill Education, 1021 2009.

[10] J. Yu, J. Zhuang, D. Yu, Modeling and analysis of a rotary direct 1023 drive servovalve Chinese Journal of Mechanical Engineering 1024 27 (5) (2014) 1064-1074. doi:10.3901/CJME. 2014.0725. 1025 127 URL https://doi.org/10.3901/CJME.2014.0725.127 1027

[11] H. Wang, G. Gong, H. Zhou, W. Wang, Steady flow torques in 1028 a servo motor operated rotary directional control valve, Energy 1029 Conversion and Management 112 (2016) 1-10. doi:10.1016/1030 j.enconman.2015.11.054

[12] M. Zhu, S. Zhao, J. Li, Design and analysis of a new high 1032 frequency double-servo direct drive rotary valve Frontiers of 1033 Mechanical Engineering 11 (4) (2016) 344-350. doi:10. 1034 1007/s11465-016-0406-x URL https ://doi.org/10.1007/s11465-016-0406-x 1036

[13] M. Zhu, S. Zhao, P. Dong, J. Li, Design and analysis of a novel 1037 double-servo direct drive rotary valve with high frequency 1038 Journal of Mechanical Science and Technology 32 (9) (2018) 1039 4313-4323. doi:10.1007/s12206-018-0829-x URL https : //doi.org/10.1007/s12206-018-0829-x

[14] E. Husley, Rotary control valve, US3135293A (1962).

16] P. Bordovsky, K. Scmitz, H. Murrenhoff, CFD Simulation and 1044 Measurement of Flow Forces Acting on a Spool Valve, in: 1045 10th International Fluid Power Conference, Dresden, Germany, 1046 2016, pp. 473-484

[17] E. Lisowski, G. Filo, CFD analysis of the characteristics of 1048 a proportional flow control valve with an innovative opening 1049 shape, Energy Conversion and Management 123 (2016) 15-28. 1050 doi:10.1016/j.enconman.2016.06.025

[18] M. Zhu, S. Zhao, J. Li, P. Dong Computational fluid dynamics 1052 and experimental analysis on flow rate and torques of a servo 1053 direct drive rotary control valve, Proceedings of the Institution 1054 of Mechanical Engineers, Part C: Journal of Mechanical Engineering Science doi:10.1177/0954406218756449

[19] Ivan Okhotnikov, Siamak Noroozi, Philip Sewell, Philip Godfrey, Evaluation of steady flow torques and pressure losses in a rotary flow control valve by means of computational fluid dynamics, International Journal of Heat and Fluid Flow 64 (2017) 89-102. doi:https://doi.org/10.1016/j. ijheatfluidflow.2017.02.005

[20] D. C. Wilcox, Turbulence Modeling for CFD, 3rd Edition, DCW Industries, Inc, 2006

[21] SolidWorks, SolidWorks Flow Simulation (2015).

[22] A. Palumbo, R. Paoluzzi, M. Borghi, M. Milani, Forces on a hydraulic valve spool, Proceedings of the JFPS International
Symposium on Fluid Power 1996 (3) (1996) 543-548. doi: 10.5739/isfp.1996.543

[23] SolidWorks, Enhanced Turbulence Modeling in SolidWorks Flow Simulation (2013).

[24] C. K. G. Lam, K. Bremhorst, A Modified Form of the $k-\varepsilon$ Model for Predicting Wall Turbulence, Journal of Fluids Engineering 103 (3). doi:10.1115/1.3240815

[25] A. Sobachkin, G. Dumnov, Numerical Basis of CAD-Embedded CFD, NAFEMS World Congress 2013 February (2013) 1-20.

[26] Launder, B.E. E. and Spalding, D.B. B., The numerical computation of turbulent flows, Computer Methods in Applied Mechanics and Engineering 3 (2) (1974) 269-289.

[27] E. R. V. Driest, On Turbulent Flow Near a Wall, Journal of the Aeronautical Sciences 23 (11) (1956) 1007-1011. doi: 10.2514/8.3713

[28] SolidWorks, Advanced Boundary Cartesian Meshing Technology in SolidWorks Flow Simulation (2013).

[29] T. Dell, Load-Sensing Pressure-Compensating (LSPC) Hydraulic Systems, in: Hydraulic Systems for Mobile Equipment, Goodheart-Willcox, 2017, Ch. 18.

[30] B. Nielsen, Controller Development for a Separate Meter-In Separate Meter-Out Fluid Power Valve for Mobile Applications, Ph.D. thesis, Aalborg University (2005).

[31] H. Ji, Y. Cao, Z. Wang, Y. Wang, Numerical analysis of temperature rise by throttling and deformation in spool valve, Proceedings of 2011 International Conference on Fluid Power and Mechatronics, FPM 2011 (2011) 752-756 doi:10.1109/ FPM. 2011.6045861

[32] CITGO, Product Information. CITGO A/W Hydraulic oils (2015).

[33] F. White, Fluid Mechanics, the fourth Edition, McGraw-Hill series in mechanical engineering, 1999.

[34] W. Durfee, Z. Sun, Fluid Power System Dynamics, Center for Compact and Efficient Fluid Power (CCEFP), Department of Mechanical Engineering, University of Minnesota, 2009.

[35] Hydreco, Q Series Hydraulic Gear Pumps (2017). URL https://www.hydreco.com/info-downloads/ technical-data-sheets/

[36] Shell, Industrial Hydraulics Fluid Shell Tellus S2 V32(2017). URL http://www.epc.shell.com/

[37] Kracht, Gear Type Flow Meter VC (2017). URL http://www.krachtcorp.com/wp-content/ uploads/2012/05/VC_USA_02-12_view.pdf

[38] Gems, 3100 Series and 3200 Heavy Duty Series Compact OEM Pressure Transmitters (2017).

URL https://www.gemssensors.co.uk/ /media/ files/resources/na_english/catalogpages/ catalog-h_3100series-3200series .ashx

[39] Tecnord, SJ-MRA Manual Rotary Spool Valve, 2 Way (2017). URL https://www.tecnord.com/tabelle/ cartridge-valves/mechanical-directional-pdf / SJ-MRA.pdf 